\title{
Análises de mobilidade no litoral sul de Santa Catarina entre 2000-500 anos cal AP ${ }^{1}$
}

\author{
Fabiana Terhaag Merencio* \\ Paulo DeBlasis**
}

\begin{abstract}
MERENCIO, F.T.; DEBLASIS, P. Análises de mobilidade no litoral sul de Santa Catarina entre 2000-500 anos cal AP. R. Museu Arq. Etn. 36: 59-94, 2021.
\end{abstract}

Resumo: Os sambaquis possuem uma ocupação longa e antiga no litoral sul de Santa Catarina (7500 a 1500 anos cal AP). A fase final dessa ocupação (a partir de 2000 anos cal AP) é marcada pela diminuição do número de sambaquis construídos e pelas alterações na estratigrafia, com o aumento de sedimento rico em matéria orgânica nas camadas superficiais de sambaquis mais antigos e em sítios discretos na paisagem (sambaquis tardios), que apresentam elementos de continuidade e mudança em relação à ocupação sambaquieira. Esse período é associado às transformações na paisagem costeira durante o Holoceno tardio e, também, aos processos culturais, como o gradual contato entre sambaquieiros e grupos Jê meridionais. A intensificação desse contato é registrada na presença de sítios monticulares e conchíferos com cerâmica Itararé-Taquara (1300-500 anos cal AP). Este artigo apresentará os dados de dispersão espacial e temporal de sítios ativos entre 2000-500 anos cal AP na região de Jaguaruna, através de análises de mobilidade multicritério (caminhos de menor custo) entre sambaquis tardios e sítios com cerâmica Itararé-Taquara. O objetivo é investigar a organização do território e as possivveis relações entre diferentes ocupações nesse período.

Palavras-chave: Arqueologia costeira; Sambaquis tardios; Jê do Sul; Análise de mobilidade; Caminhos de menor custo.

\section{Introdução} Oo litoral sul de Santa Catarina, na região
da paleolaguna de Santa Marta em Jaguaruna, os sambaquis são a ocupação mais

\footnotetext{
* Doutora em Arqueologia pelo Museu de Arqueologia e Etnologia, Universidade de São Paulo (MAE-USP). $<$ f.terhaag@gmail.com>

** Diretor do Museu de Arqueologia e Etnologia, Universidade de São Paulo (MAE-USP) / Doutor em Arqueologia pela Universidade de São Paulo (USP). <deblasis@usp.br>

1 Este artigo apresenta uma síntese dos métodos e resultados das análises espaciais realizadas na pesquisa de doutorado da primeira autora.
}

antiga e longeva, com datas entre 7500 a 1500 anos AP (Assunção 2010; DeBlasis et al. 2007; DeBlasis, Farias \& Kneip 2014; Giannini et al. 2010). As pesquisas realizadas no projeto Sambaquis e Paisagem constataram um declínio na construção de sambaquis entre 2000 e 1000 anos cal AP² (Kneip, Farias \& DeBlasis 2018) associado às mudanças nos processos de formação

2 Todas as datas apresentadas neste trabalho foram calibradas pelo programa OxCal v.4.3 (Bronk Ramsey 2014), utilizando a curva atmosférica ShCall 13 para carvão, curva marinha Marine 13 para conchas com correção do delta $\mathrm{R}$ de 220 20 (Eastoe et al. 2002) e curva mista para ossos humanos (Scheel-Ybert 2019). 
e composição estratigráfica, que é identificada pela presença de sedimento arenoso escuro com alto teor de matéria orgânica (Bendazzoli 2007; Nishida 2007).

De forma resumida, verifica-se na bibliografia que as alterações nos processos de construção estão presentes: (1) nas camadas superficiais de alguns sambaquis antigos; (2) em sítios rasos, designados como sambaquis tardios (DeBlasis, Farias \& Kneip 2014), e que não apresentam cerâmica Itararé-Taquara; e, por último, (3) em sitios monticulares (DeBlasis, Farias \& Kneip 2014) com a presença de cerâmica Itararé-Taquara, também denominados sítios mistos ${ }^{3}$ (Villagran 2012).

O declínio da ocupação sambaquieira, segundo pesquisas, teria sido provocado tanto por mudanças ambientais causadas pelas variações do nível relativo do mar bem como por processos culturais, hipoteticamente, associados à chegada de grupos ceramistas no litoral, relacionados com a tradição Itararé-Taquara (Beck 1972; DeBlasis \& Gaspar 2009; DeBlasis et al. 2007; Gaspar et al. 2007, 2008; Giannini et al. 2010; Hurt 1974; Villagran 2012, 2013). A tradição Itararé-Taquara (Araujo 2007) é associada aos grupos linguísticos pertencentes ao ramo meridional da família Jê, etnograficamente e historicamente conhecidos como Kaingang ${ }^{4}$ e Laklãnõ-Xokleng (Gakran 2015). Segundo estimativas linguísticas, a família Jê tem sua origem no Brasil central, com dispersão entre 3000-2500 anos AP (Noelli 2000; Urban 1992; Wiesemann 1978).

A partir da elaboração de um banco de dados georreferenciado dos sítios registrados no litoral sul de Santa Catarina, este artigo apresentará os resultados das análises de mobilidade multicritério realizadas para estimar

3 Segundo Villagran (2012: 82), os sítios mistos apresentam padrão estratigráfico do tipo montículo ictiológico, e são formados por "misturas maciças ou mal estratificadas de areia com ossos de peixe, carvão, conchas ocasionais e, em alguns casos, fragmentos cerâmicos”.

4 Borba (1908) reuniu diversos grupos indigenas falantes da língua Jê sob a denominação "kaingang", simplificando uma multiplicidade de grupos: Coronado, Coroado, Gualacho, Guaianá, Camé, Pinaré etc. (Veiga 2006). o deslocamento tanto em terreno como em água, entre os sambaquis tardios e os sítios com cerâmica Itararé-Taquara ativos entre 2000-500 anos cal AP. O objetivo foi investigar a organização do território e as possíveis relações entre as diferentes ocupações nesse período. Os critérios selecionados para avaliar o custo de deslocamento foram: (1) oscilações no nível relativo do mar (NRM); (2) declividade do terreno; (3) hidrografia, considerando a ordem dos cursos d'água (Strahler 1957); e (4) as grandes lagoas, identificadas como áreas de baixo custo de circulação, considerando que se tratam de grupos plenamente adaptados a ambientes aquáticos (Prates \& Bonomo 2017) e com correlação entre tempo e distância percorrida por canoas a remo em estudos etnográficos (Ames 2002; Gustas \& Supernant 2017; Livingood 2012). Os modelos gerados foram avaliados em levantamento extensivo, conduzido a partir da purposive survey, cujo foco é maximizar a probabilidade de detecção de sítios com as mesmas características (Banning 2002).

\section{Contexto arqueológico}

O litoral sul de Santa Catarina, em especial a região de Jaguaruna, apresenta uma densa ocupação vinculada a diferentes grupos culturais, destacando-se os sítios conchíferos, designados como sambaquis, com registro a partir de 7500 anos cal AP (Assunção 2010; DeBlasis, Farias \& Kneip 2014; DeBlasis et al. 2007; Giannini et al. 2010); sítios com cerâmica ItararéTaquara a partir de 1300 anos cal AP (DeBlasis, Farias \& Kneip 2014), inicialmente identificada como cerâmica sambaquieira ou não guarani (Schmitz 1958); e sítios com cerâmica guarani, com registro mais antigo em 600 anos cal AP (Milheira 2010) (Fig. 1).

A faixa temporal registrada para os sambaquis se estende entre 7500-1500 anos cal AP (DeBlasis, Farias \& Kneip 2014), com ápice registrado entre 5000-2000 anos cal AP, período em que se verifica o aumento do número de sítios e de processos de complexificação social que se expressam, também, em intensa monumentalização funerária (Kneip, Farias \& 
DeBlasis 2018). O período seguinte, a partir de 2000 anos cal AP, caracteriza-se pelo declínio da ocupação sambaquieira, verificado pela menor densidade de sítios ativos (Kneip, Farias \& DeBlasis 2018) e por mudanças na composição estratigráfica, com a redução do uso de conchas e o aumento da deposição de sedimento arenoso escuro, rico em matéria orgânica (Bendazzoli 2007; Menezes 2009; Nishida 2007; Villagran, 2008, 2012; Villagran et al. 2010).

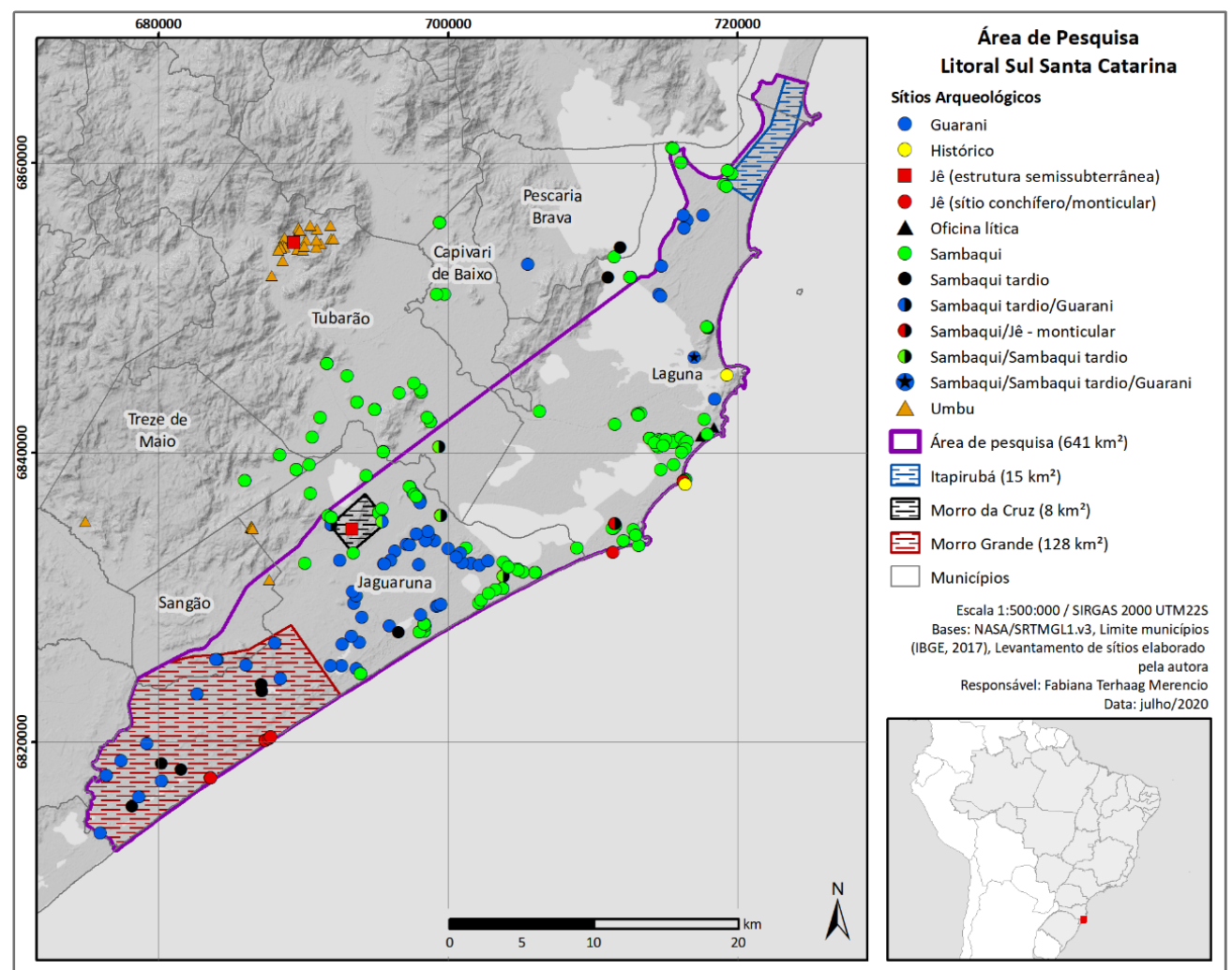

Fig. 1: Mapa de sítios arqueológicos registrados no litoral sul de Santa Catarina.

Fonte: elaborado pelos autores.

Essas alterações são registradas nas camadas superficiais de alguns sambaquis antigos, como o Jabuticabeira II (3165-1182 anos cal AP) (Bendazzoli 2007; Nishida 2007; Villagran 2008). Também estão presentes em sítios conchíferos rasos e sem cerâmica, denominados sambaquis tardios $^{5}$ (DeBlasis,

5 Na bibliografia, sítios com essas características receberam diversas nomenclaturas, destacando-se: sítios semienterrados, sambaquis sujos ou sítios rasos de sepultamento por Rohr (1969, 1984); sítios rasos em Prous (1992) e Lima (2000); acampamentos litorâneos em Prous (1992) e Villagran (2012) e sítios conchiferos rasos por Oppitz (2015).
Farias \& Kneip 2014), termo utilizado neste e em outros trabalhos em uma perspectiva de longa duração, enfatizando as continuidades em meio às mudanças registradas. São sítios que apresentam camadas pouco espessas (entre 40-60 cm), composição malacológica distinta e conjunto artefatual lítico e ósseo semelhante ao registrado nos sambaquis. Exemplificam essa categoria no litoral sul os sítios: Içara 01 (Schmitz et al. 1999), Lagoa dos Freitas (Santos, Pavei \& Campos 2016), Morro Grande I e II, Arroio da Cruz II e Arroio da Cruz de Dentro (Rohr 1969, 1984). 
Os processos de mudança no registro arqueológico nessa região também são verificados no período seguinte, entre 1300 500 anos cal AP, em duas categorias de sítios que apresentam cerâmica Itararé-Taquara. Os sítios monticulares, também denominados sítios mistos (Villagran 2012), apresentam idades entre 1276-565 anos cal AP (DeBlasis, Farias \& Kneip 2014), e, embora a estratigrafia seja composta igualmente por camadas de sedimento escuro, rico em matéria orgânica, diferencia-se dos sambaquis tardios pela menor densidade de conchas. A composição faunística registrada nesses sítios pode ser semelhante (Villagran 2012) ou distinta (DeBlasis, Farias \& Kneip 2014) da presente nos sambaquis e sambaquis tardios. No litoral sul, exemplos desses sítios são Galheta IV e Costão do Ilhote de Santa Marta (DeBlasis et al. 2007; DeBlasis, Farias \& Kneip 2014; Villagran 2012, 2013). Além desses sítios, a cerâmica ItararéTaquara é igualmente registrada em sítios conchiferos com idades entre 1041-512 anos cal $\mathrm{AP}$, e, ao contrário dos sítios monticulares, apresentam pacotes de conchas pouco espessos na estratigrafia. Exemplos desses sítios são Arroio da Cruz I ${ }^{6}$ e Campo Bom I, II e III (Assunção 2010; DeBlasis, Farias \& Kneip 2014; DeBlasis et al. 2007; Farias et al. 2018).

Os dados gerados pelas pesquisas em diferentes porções litorâneas levantam hipóteses de que o declínio da ocupação sambaquieira foi devido tanto a fatores ambientais como a processos culturais. Quanto aos fatores ambientais, destacam-se as alterações na paisagem a partir de 2000 anos cal AP, como as variações do nível relativo do mar que resultaram no fechamento e assoreamento dos corpos lagunares e consequente dessalinização dos corpos d'água.

6 O Grupep-Unisul (Farias et al. 2018) identificou a localização correta dos sítios Arroio da Cruz I e Campo Bom I ao comparar o mapa produzido por Rohr (1969) e os sítios registrados na região. Desse modo, é importante apontar que o sítio Arroio da Cruz I, mencionado por Kneip (2004) e outros trabalhos, é na realidade o sítio Campo Bom I, localizado em balneário homônimo, enquanto o Arroio da Cruz I está localizado mais ao sul, conforme indicado por Rohr (1969). Esses sítios integram o doutorado de Anderson Tognoli, em curso no MAE-USP.
Em decorrência, houve a diminuição das áreas de mangue e de espécies malacológicas importantes para sambaquieiros, como ostras e berbigões, e sem a redução na predação de moluscos, exauriu-se esse recurso alimentar (DeBlasis et al. 2007; Gaspar et al. 2008; Lima 2000; Villagran 2013).

Com relação aos processos culturais, aponta-se que a migração de grupos ceramistas para o litoral, indicada pela presença da cerâmica Itararé-Taquara nas camadas superficiais de sambaquis e sítios monticulares, teria provocado uma desestabilização no sistema sociocultural sambaquieiro (Beck 1972; DeBlasis et al. 2007; DeBlasis \& Gaspar 2009; Gaspar et al. 2007, 2008; Villagran 2012, 2013). A cerâmica Itararé-Taquara possui características distintas e bem definidas, como a presença de vasilhames de pequenas dimensões e atributos tecnológicos semelhantes: antiplástico mineral (tanto grosso como fino), queima oxidante incompleta com núcleo escuro e técnica de manufatura incerta, com o roletado sendo identificado em proporções pequenas em diversos conjuntos, possivelmente devido ao uso de técnicas mistas como roletado, paddle and anvil e paleteado (Parellada 2008; Saldanha 2005; Souza 2009).

O conjunto tecnológico ItararéTaquara também é caracterizado por uma variedade de ocupações, como sítios lito-cerâmicos a céu aberto, inscrições rupestres, grutas com sepultamentos, além de construções em terra com finalidades ritualísticas, funerárias e residenciais, como montículos, aterros, estruturas anelares e semissubterrâneas (Noelli 1999; Reis 2002; Beber 2004; Araujo 2007; Souza \& Copé 2010; Corteletti 2012; Souza 2012; Iriarte et al. 2014; DeBlasis, Farias \& Kneip 2014). A área de dispersão desse conjunto corresponde aos estados do sul (Paraná, Santa Catarina e Rio Grande do Sul), São Paulo e Mato Grosso do Sul, além da província de Misiones, na Argentina. $\mathrm{O}$ amplo território contempla ambientes muito distintos: áreas litorâneas (restingas e lagoas), encostas de serras (Mata Atlântica), topos de serras (mata com araucária) e vales localizados no extremo oeste (onde 
predomina a floresta estacional semidecidual) (Schmitz 1988; Prous 1992; Noelli 2005; Araujo 2007; Corteletti 2012, 2013; Iriarte et al. 2014; Corteletti et al. 2015).

Os dados arqueológicos indicam uma expansão territorial desse conjunto tecnológico no planalto meridional em aproximadamente 1000 anos cal AP, concomitante à expansão da floresta de araucária, entre 1410-900 anos cal AP. Nesse período, nota-se no registro arqueológico uma maior densidade de construções em terra, sobretudo estruturas semissubterrâneas, anelares e montículos (Bitencourt \& Krauspenhar 2006; Iriarte \& Behling 2007; Corteletti 2012, 2013; Corteletti et al. 2015; Souza 2012; Iriarte et al. 2014, 2016).

As idades mais recuadas estão em São José do Cerrito, planalto de Santa Catarina, no sítio Boa Parada I (SC-CL-43), que é caracterizado pela presença de estruturas semissubterrâneas. Contudo, a datação de 2837-2496 anos cal AP (2640 \pm 40 ; Beta 275577) é proveniente dos níveis inferiores da parte externa de uma das estruturas, sem a presença de cerâmica (Schmitz \& Rogge 2011, 2013; Schmitz et al. 2010, 2013a, 2013b).

Os registros mais antigos da cerâmica Itararé-Taquara estão localizados em diversos locais: no planalto paranaense, em Sengés, com idade aproximada de 2298-1273 anos cal

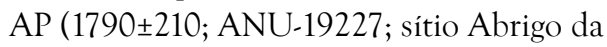
Janela) (Parellada 2005); no nordeste do Rio Grande do Sul, relacionada à Fase Guatambu, entre 1905-1487 anos cal AP (1810 \pm 85 ; SI-813; sítio RS-P-12) (Schmitz 1988); e na região do Alto Taquari, onde foi registrada entre 18201140 anos AP (1530 \pm 170 ; Lacivid-40115; sítio Müzel) (Araujo 2001). Tais dados corroboram o modelo linguístico de dispersão de grupos Jê a partir do Brasil central para a região sul, com caminho pela porção leste de São Paulo e Paraná (Araujo 2007; Noelli \& Souza 2017), e reforçam a hipótese levantada por Araujo (2007) de que a tradição Itararé-Taquara teria origem na porção norte de São Paulo, divisa com Minas Gerais, área onde foram registradas estruturas semissubterrâneas associadas à cerâmica Una (relacionada a populações Jê) (Corrêa 2009).
Quanto à cronologia da cerâmica ItararéTaquara em Santa Catarina, trabalhos apontam que o registro mais recuado estaria no planalto, no sítio Rincão dos Albinos (SC-CL-70), com idade entre 1066-90 anos cal AP (1140 \pm 40 ; Beta-293591) (Schmitz \& Rogge 2011). Contudo, o levantamento das datas disponíveis para os sítios com cerâmica Itararé-Taquara no litoral catarinense aponta para dados mais recuados em diversos pontos: no litoral sul, no sítio Galheta IV (1276-1088 anos cal AP; 1360 40 ; Beta 280010) (DeBlasis, Farias \& Kneip 2014); no litoral central, no sítio da Tapera (1253-1073 anos cal AP; 1330 \pm 30 ; Beta-384036) (Oppitz 2015); e no litoral norte, nos sítios Enseada I (1290-1171 anos cal AP; $1390 \pm 40)^{7}$ e Laranjeiras II (1262-1080 anos cal AP;

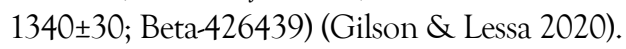

\section{Evidências de interação além da cerâmica: continuidades e mudanças}

As evidências de interação entre grupos sambaquieiros e Jê meridionais não se restringem somente à presença da cerâmica ItararéTaquara; são verificadas também em pesquisas bioantropológicas, de paleodieta e paleogenéticas. De acordo com pesquisas craniométricas realizadas em indivíduos sepultados em sítios com cerâmica Itararé-Taquara e em sambaquis no litoral norte e na Ilha de Santa Catarina, foram verificados, na maior parte da amostra, elementos de continuidade e afinidade genética entre os indivíduos sepultados nos sítios com cerâmica e sambaquis, e não com os sepultamentos do planalto (séries ceramistas). Em menor proporção, foi observado um distanciamento dos conjuntos de sítios com cerâmica em relação aos sambaquis, levantando a hipótese de que a cerâmica estaria associada à presença de populações distintas (Neves 1988; Okumura 2008; Hubbe et al. 2009). No litoral central e na ilha de Santa Catarina, pesquisas bioantropológicas observaram ainda o aumento de traumas vinculados a episódios de violência

7 Divulgada por DeMasi durante evento em 2001, sem informação de contexto e código de laboratório (Bandeira 2004). 
em indivíduos autóctones sepultados em sítios com cerâmica Itararé-Taquara, indicando que o contato entre os grupos nessa área resultou em alguns momentos de conflito (Lessa 2006; Lessa \& Scherer 2008).

As pesquisas de paleodieta realizadas em sítios desse contexto, incluindo as séries com cerâmica, apontam que houve continuidade da dieta marinha, sobretudo no consumo de peixes e de espécies de alto nível trófico, sendo observadas algumas variações nos sítios mais tardios em relação à diminuição do consumo de animais marinhos de alto nível trófico ou ao aumento da ingestão de recursos terrestres (Bastos 2009; DeMasi 2001; Colonese et al. 2014; Oppitz 2015; Klokler, Gaspar \& Scheel-Ybert 2018).

As análises de micro vestígios de cálculos dentários, realizadas em indivíduos sepultados no sambaqui Morro do Ouro, no litoral norte de Santa Catarina, constataram o consumo, em alguns momentos, de vegetais cultivados, assim como os indivíduos de sítios com cerâmica Itararé-Taquara (Enseada I, Itacoara e Forte Marechal Luz) igualmente consumiram vegetais coletados, como indica o registro de fitólitos e grânulos de amido de sementes de Araucária angustifólia (pinhão), sugerindo que os grupos que ocuparam a faixa litorânea tiveram algum tipo de acesso ao mesmo recurso (Wesolowski 2007). Nesse aspecto, os resultados apontam, em sua maioria, para a continuidade da população sambaquieira associada à mudança na composição estratigráfica e à presença da cerâmica Itararé-Taquara, não sendo descartada, contudo, a presença de grupos do planalto no litoral.

Em outras regiões do litoral, as pesquisas realizadas sobre o tema apontam a presença de elementos de interação e comportamentos distintos, como indícios de trocas materiais, observadas pela semelhança de artefatos registrados na região dos lagos no litoral do Rio de Janeiro, como pontas em osso (Gaspar et al. 2007), e em Santa Catarina, com o registro de zoólitos em sítios do planalto e de conjuntos líticos do planalto em sítios do litoral (Silva et al. 1990; Prous 1992).

Com base nesses estudos, pesquisadores têm apontado que os sítios com cerâmica
Itararé-Taquara seriam resultado da ocupação sambaquieira e que a presença da cerâmica Itararé-Taquara seria um indicador da intensificação de contato entre ambos os grupos (Villagran 2013).

A partir desse contexto, este artigo apresenta os dados referentes à dispersão espacial e temporal de sítios ativos entre 2000 a 500 anos cal AP no litoral sul de Santa Catarina, com foco em sambaquis tardios e sítios com cerâmica Itararé-Taquara. O objetivo foi verificar a organização do território nesse período e as possíveis relações entre os conjuntos. Foram aplicados métodos de geoprocessamento sobretudo de sistemas de informação geográfica, para realização de análises multicritério de mobilidade (caminhos de menor custo ou least cost path) entre sambaquis tardios e sítios com cerâmica ItararéTaquara ativos em três faixas cronológicas: 2000-1500, 1500-1000 e 1000-500 anos cal AP.

\section{A aplicação dos sistemas de informação geográfica na pesquisa}

Os sistemas de informação geográfica (SIG) foram desenvolvidos a partir de 1960 por diferentes organizações de formas independentes, sendo suas origens difíceis de traçar (Coppock \& Rhind 1991). De forma geral, têm se designado erroneamente como SIG apenas os softwares desenvolvidos para processar dados geográficos (como o ArcGIS ou Quantum GIS). No entanto, os SIGs são compostos por diversos elementos, como: informações (obtidas de forma primária em levantamentos de campo, ou secundária através de mapas, modelos rasters e vetoriais $)^{8}$, métodos de análise dos dados (uso de procedimentos específicos visando obter resultados para responder a uma questão), softwares (programas de interface

8 Modelos de raster são utilizados para expor dados espaciais contínuos em forma de células, como elevação do terreno, densidade de material arqueológico ou de população. Os modelos vetoriais (shape), representam dados espaciais não contínuos em forma de pontos, linhas e polígonos, sendo utilizados em limites territoriais, áreas de fonte de matériaprima ou sítios arqueológicos (Wheatley \& Gillings 2002). 
amigável utilizados na coleta, armazenamento, processamento e análise de dados) e hardware (equipamentos e sistemas necessários para o funcionamento dos softwares) (Rosa 2005).

Os primeiros trabalhos envolvendo SIG na arqueologia são do final da década de 1980 e tinham como principais objetivos: a análise espacial das relações entre paisagem e grupos humanos e o desenvolvimento dos primeiros modelos preditivos, utilizados em trabalhos preventivos. A partir da metade de 1990, com a influência da arqueologia da paisagem, melhorias na interface dos softwares e a sua consequente popularização, a aplicação de SIG voltou-se para a elaboração de modelos e análises espaciais, como o delineamento de bacias hidrográficas, visibilidade intersítio, polígonos de Thiessen, análise de captação do local e caminhos de menor custo (CMC) (Hu 2012).

Os modelos de CMC têm como objetivo indicar possiveis caminhos que apresentem menor custo energético ou de tempo no deslocamento entre dois pontos. Para tanto, foram consideradas as características do terreno, como elevação e declividade, além de barreiras naturais, como cursos hidrográficos (Herzog 2014). Exemplos de análises de mobilidade entre sítios arqueológicos no Brasil, em especial no contexto Jê meridional, são encontradas em Corteletti (2012), D’Ávila (2017), Silva (2018) e Kozlowski \& Corteletti (2019).

A realização de análises de mobilidade na arqueologia pressupõe que provavelmente ocorrerão sítios ou vestígios arqueológicos nos caminhos estimados, o que pode ajudar a compreender a organização e o uso da paisagem por grupos pretéritos (Whitley \& Hicks 2003; Brantings 2012; White 2015). Contudo, é importante ressaltar que os resultados obtidos simplificam os aspectos de mobilidade, pois, em sua maioria, partem de modelos idealizados de deslocamento realizados em menor tempo ou custo energético, podendo também ser pautados na seleção de critérios de avaliação insuficiente. Tendo em mente tais limitações e restrições, destaca-se que os modelos de CMC podem apresentar benefícios na pesquisa quando utilizados de forma exploratória, e não como dado concreto (Brantings 2012).
Para desenvolver as análises de CMC nesta pesquisa, foi adotada uma perspectiva adaptada da pesquisa multiestágios, com uso de diferentes técnicas, como proposto por Redman (1973) e Schiffer, Sullivan \& Klinger (1978). Foram definidas cinco etapas principais: (1) levantamento de informações prévias; (2) reconhecimento de campo; (3) escavação; (4) análises espaciais; e (5) levantamento extensivo pautado na abordagem purposive survey (Banning 2002).

O levantamento de informações prévias (background studies) (Schiffer, Sullivan \& Klinger 1978) consistiu na compilação de dados dos sítios registrados no litoral sul de Santa Catarina para elaborar um banco de dados georreferenciados, por meio da consulta de artigos, dissertações e teses (em especial Rohr 1969, 1984; Kneip 2004; DeBlasis et al. 2007; Assunção 2010; Farias \& Kneip 2010; Milheira 2010; Oliveira 2010; DeBlasis, Farias \& Kneip 2014; Attorre 2015; Campos 2015; Santos, Pavei \& Campos 2016; Centro Nacional de Arqueologia 2019) (Fig. 1). Na sequência, foi realizado o reconhecimento de campo (reconnaissance stage) (Schiffer, Sullivan \& Klinger 1978), onde foram inspecionados sambaquis tardios e sítios com cerâmica Itararé-Taquara, identificados na etapa anterior, para coleta de informações sobre o estado de preservação, acessibilidade e viabilidade de escavação. Dentre os sítios de interesse, três foram selecionados para escavação (dois sambaquis tardios, Morro Grande I e II, e um sítio com estruturas semissubterrâneas, Morro da Cruz).

Todas as informações reunidas nas etapas prévias retroalimentaram o banco de dados georreferenciado utilizado para realizar as análises espaciais, em especial de mobilidade, com o objetivo de investigar aspectos da organização do território e a relação dos sítios entre si e a paisagem (Conolly \& Lake 2006; Wheatley \& Gillings 2002). Para verificar o potencial das análises espaciais geradas, os resultados obtidos foram avaliados a partir do levantamento extensivo, conduzido pela purposive survey, que tem como intuito maximizar a probabilidade de detecção de sítios com as mesmas características (Banning 2002). 
Procedimentos para geração dos modelos de mobilidade

As análises de mobilidade multicritério realizadas neste trabalho seguiram os procedimentos indicados por Whitley \& Hicks (2003), Howey (2007), Livingood (2012), Yanchar (2013) e White (2015), estimando o custo de deslocamento em terra e água. Os modelos de $\mathrm{CMC}$ foram gerados considerando os sítios arqueológicos com idades aproximadas e ativos em três faixas cronológicas: 2000$1500,1500-1000$ e 1000-500 anos cal AP. Esse procedimento foi adotado como ferramenta heurística para evitar a geração de caminhos de mobilidade entre sítios não contemporâneos. Os critérios selecionados para avaliação do custo de deslocamento foram: (1) oscilações no nível relativo do mar; (2) declividade do terreno; (3) hidrografia, considerando a ordem dos cursos d'água (Strahler 1957); e (4) áreas das grandes lagoas, consideradas áreas de baixo custo de circulação com base na correlação entre tempo e distância percorrida por canoas a remo (Livingood 2012; Gustas \& Supernant 2017).

Para estimar os modelos de mobilidade na faixa litorânea, é preciso atentar para as alterações na paisagem resultantes das flutuações do NRM, pois tais oscilações influenciam as dimensões tanto das áreas terrestres como dos corpos lagunares disponíveis para deslocamento. Em testes prévios dos caminhos de mobilidade, nos quais foram considerados somente critérios do terreno e hidrografia, os caminhos gerados interligando sítios da margem direita da desembocadura da lagoa de Santo Antônio com ocupações da margem esquerda, como Caieira, Morro do Peralta e Cabeçuda, contornavam toda a lagoa de Santo Antônio, Imaruí e Mirim, evitando a massa d'água, e, portanto, não refletiam os aspectos de mobilidade de grupos litorâneos. No entanto, tais caminhos tornam-se interessantes na medida em que há registros de sítios nas dunas de Itapirubá, com presença de cerâmica Itararé-Taquara (Farias \& Kneip 2010).

Considerar somente o terreno para o deslocamento é inadequado para a região de estudo, tendo em vista que os recursos aquáticos correspondem a uma parcela significativa da subsistência tanto de grupos sambaquieiros (Figuti 1993; DeMasi 2001; Klokler et al. 2010) como das ocupações com cerâmica Itararé-Taquara (Hansel \& Schmitz 2006; Colonese et al. 2014). Além disso, são grupos plenamente adaptados a ambientes aquáticos (Prates \& Bonomo 2017) e que possuem no ambiente lagunar um forte elemento de integração social com o compartilhamento de um "aquatório", como ressaltam Kneip, Farias \& DeBlasis (2018: 47).

A partir disso, foram estimados os limites costeiros pelo modelo de variação do NRM proposto por Angulo et al. (1999) e Angulo, Lessa \& Souza (2006). De acordo com Kneip (2004) e Kneip \& Mello (2018), o máximo de $2,3 \mathrm{~m}$ acima da cota atual teria ocorrido entre 5800-4400 anos cal AP. Para o período investigado, entre 2000 a 500 anos cal AP, foram utilizadas duas cotas: em 1800 anos cal AP, o NRM seria de $1 \mathrm{~m}$ acima do nível atual, e entre 1800-900 anos cal AP, de 0,5m (Kneip \& Mello 2018: 256). Os dados de variação do nível do mar incluídos na análise foram de $1 \mathrm{~m}$ para 2000-1500 anos cal AP; 0,5m para 1500-1000 anos cal AP; e limites atuais para 1000-500 anos cal AP.

Em relação ao terreno, o critério comumente utilizado para calcular a superfície de custo é a declividade do terreno em graus (Herzog 2014). Em termos gerais, quanto maior a declividade do terreno, como terrenos íngremes, maior será a dificuldade para o deslocamento, e, em terrenos planos, menor será o custo (tanto em termos energéticos como de tempo). Contudo, como ressaltam Bell \& Lock (2000), não há uma relação linear entre o ângulo do terreno e o esforço para transpô-lo. Ou seja, o custo de deslocamento não aumenta proporcionalmente à declividade do terreno. Para estimar o custo adequado da declividade, foram adotados neste trabalho os parâmetros propostos por Bell \& Lock (2000), por meio da fórmula: custo relativo $=\frac{\tan (\theta)}{\tan \left(1^{\circ}\right)}$, resultando em um aumento drástico no custo em terrenos com declividade igual ou superior à $60^{\circ}$.

A rede hidrográfica e lagunar foram incluídas considerando a ordem dos cursos d'água (Strahler 1957), na qual há uma relação entre o 
tamanho do curso e o número de afluentes que o formam. Desse modo, foi atribuído um baixo custo para transposição de cursos de primeira ordem, que correspondem às nascentes, e um custo médio para os rios principais, de oitava ordem, como Urussanga e Tubarão. Para estimar o custo de deslocamento na região das grandes lagoas (Santo Antônio, Imaruí e Mirim), foram considerados dados sobre a relação entre tempo e distância percorrida por canoas a remo. De acordo com Livingood (2012) e Gustas \& Supernant (2017) que aplicaram procedimentos semelhantes para inclusão da água nos modelos de mobilidade, a velocidade média de uma canoa totalmente carregada seria entre 4 a $5 \mathrm{~km} / \mathrm{h}$, podendo percorrer uma distância de $38 \mathrm{~km}$ em 8 horas. $\mathrm{Na}$ área de pesquisa, a distância isotrópica máxima entre sítios no entorno da lagoa é de aproximadamente $27 \mathrm{~km}^{9}$, sendo possível completar o percurso em 6 horas.

A manipulação dos dados geográficos (Tabela 1) foi realizada por meio do software ArcGIS Pro. O fluxo de trabalho no ArcGIS para geração do CMC consistiu em três etapas principais: (1) criação de superfícies de custo multicritério; (2) estimativa do custo acumulado; e, por fim, (3) cálculo dos caminhos de menor custo.

\begin{tabular}{|c|c|c|}
\hline Variável & Classe & Descrição/Fonte \\
\hline Sítios arqueológicos & Vetor & $\begin{array}{l}\text { Sítios arqueológicos registrados na área de pesquisa. Foram } \\
\text { gerados três vetores com os pontos de sítios ativos nas três } \\
\text { faixas cronológicas estimadas. }\end{array}$ \\
\hline Elevação (m) & Raster & $\begin{array}{l}\text { Modelo digital de elevação (DEM) e resolução espacial de 30m } \\
\text { obtidos a partir do SRTM (Shuttle Radar Topography Mission) } \\
\text { (National Aeronautics and Space Administration 2013). }\end{array}$ \\
\hline $\begin{array}{l}\text { Nível relativo do mar (NRM) em } \\
0,5 \text { e } 1 \mathrm{~m}\end{array}$ & Raster & Cálculo de áreas suscetíveis à inundação a partir da elevação. \\
\hline Unidades hidrográficas com lagos & Vetor & $\begin{array}{l}\text { Limites da costa com NRM atual além dos principais lagos } \\
\text { (Empresa de Pesquisa Agropecuária e Extensão Rural de Santa } \\
\text { Catarina 2007). }\end{array}$ \\
\hline $\begin{array}{l}\text { Limites da costa com NRM 0,5m } \\
\text { e } 1 \mathrm{~m}\end{array}$ & Vetor & $\begin{array}{l}\text { Limites da costa adaptado a partir dos rasters com NRM de } \\
0,5 \mathrm{~m} \text { e } 1 \mathrm{~m} .\end{array}$ \\
\hline Elevação (m) & Raster & $\begin{array}{l}\text { Modelo digital de elevação com os limites de costa com NRM } \\
0,5 \mathrm{~m} \text { e } 1 \mathrm{~m} \text {. }\end{array}$ \\
\hline Declividade $\left(^{\circ}\right)$ & Raster & $\begin{array}{l}\text { Declividade da superfície em graus, gerado com base nos } \\
\text { rasters de elevação com NRM em } 0 \mathrm{~m}, 0,5 \mathrm{~m} \text { e } 1 \mathrm{~m} \text {. }\end{array}$ \\
\hline Declividade reclassificada & Raster & Reclassificação dos rasters de declividade. \\
\hline Hidrografia - Trecho drenagem & Vetor & $\begin{array}{l}\text { Base Hidrográfica Ottocodificada (BHO } 2017 \text { v. 1.5) (Agência } \\
\text { Nacional de Águas 2017) com a ordem de curso d'água de } \\
\text { Strahler (1957) }\end{array}$ \\
\hline Hidrografia - Trecho drenagem & Raster & $\begin{array}{l}\text { Obtido a partir do vetor de hidrografia utilizando como parâ- } \\
\text { metro a ordem de curso d'água de Strahler (1957). }\end{array}$ \\
\hline Hidrografia reclassificada & Raster & Reclassificação do raster de hidrografia. \\
\hline Superfície de custo irrestrita & Raster & $\begin{array}{l}\text { Soma dos rasters reclassificados de declividade e hidrografia. } \\
\text { O resultado é um arquivo que apresenta baixo custo de deslo- } \\
\text { camento em alto mar. }\end{array}$ \\
\hline Superfície de custo restrita & Raster & $\begin{array}{l}\text { Superfície de custo obtida a partir da identificação de áreas } \\
\text { que deveriam ser evitadas no deslocamento, como alto-mar. }\end{array}$ \\
\hline
\end{tabular}

Tabela 1: Dados primários e secundários utilizados para a geração dos caminhos de menor custo.

Fonte: elaborado pelos autores.

9 Com NRM de 1m, entre os sítios Congonhas III e Ponta das Laranjeiras II. 
A primeira etapa consistiu na geração das superfícies de custo multicritério, que apresentam o custo de deslocamento entre as células do raster, com base na delimitação dos limites da costa para cada faixa temporal, estipulada neste trabalho, na declividade do terreno e nos cursos d'água. Esse arquivo foi obtido por meio dos procedimentos abaixo:

1. Cálculo das áreas suscetíveis à inundação com NRM em 0,5m e $1 \mathrm{~m}$, conforme estimado por Angulo et al. (1999), no raster de elevação, seguindo os procedimentos indicados por Li et al. (2009) (spatial analyst tools $>$ map algebra $>$ raster calculator), inserindo as seguintes fórmulas: "DEM_raster" $<=1$ e "DEM_raster" $<=0,5)$;

2. A partir desses dados, o vetor com os limites da costa atual foi editado manualmente de modo a contemplar as variações do NRM para as duas situações: $0,5 \mathrm{~m}$ e $1 \mathrm{~m}$; (edit>modify>edit vertices) (Fig. 2); 3. Em seguida, foram excluídas as áreas de mar e lagos com NRM em 0m, 0,5m e $1 \mathrm{~m}$ no raster de elevação a partir dos respectivos vetores de limites da costa editados previamente (spatial analyst tools>extraction > extract by mask);

4. Criação do arquivo de declividade em graus a partir dos rasters de elevação com NRM de $0 \mathrm{~m}, 0,5 \mathrm{~m}$ e $1 \mathrm{~m}$ (spatial analyst tools>surface>slope);
5. Conversão do vetor de hidrografia em raster, selecionando como value field a ordem de curso d'água de Sthraler (1957) (conversion tools $>$ to raster> polyline to raster);

6. Reclassificação dos arquivos de declividade e hidrografia com atribuição de custo (Tabela 2), segundo parâmetros de Bell \& Lock (2000) e Riris (2014) (spatial analyst>reclass $>$ reclassify). Com relação à declividade, os intervalos dos valores originais apresentados na Tabela 2 foram definidos no ArcGIS a partir dos valores de quebra inseridos: $1^{\circ}, 5^{\circ}, 10^{\circ}, 15^{\circ}, 20^{\circ}, 30^{\circ} \mathrm{e}$ $75^{\circ}$. Para estimar o custo do deslocamento na região das grandes lagoas, foi atribuído um baixo valor (1) para as células sem dados (NoData) na reclassificação do raster de declividade.

7. Elaboração da superfície de custo a partir da soma dos arquivos reclassificados de declividade e hidrografia (spatial analyst tools>map algebra>raster calculator);

8. Para indicar áreas que deveriam ser evitadas no deslocamento, como as pequenas lagoas e o mar, foi aplicado um novo recorte a partir do vetor de limites da costa, editado manualmente, excluindo o contorno somente das lagoas de Santo Antônio, Imaruí e Mirim (procedimentos 2 e 3 ).

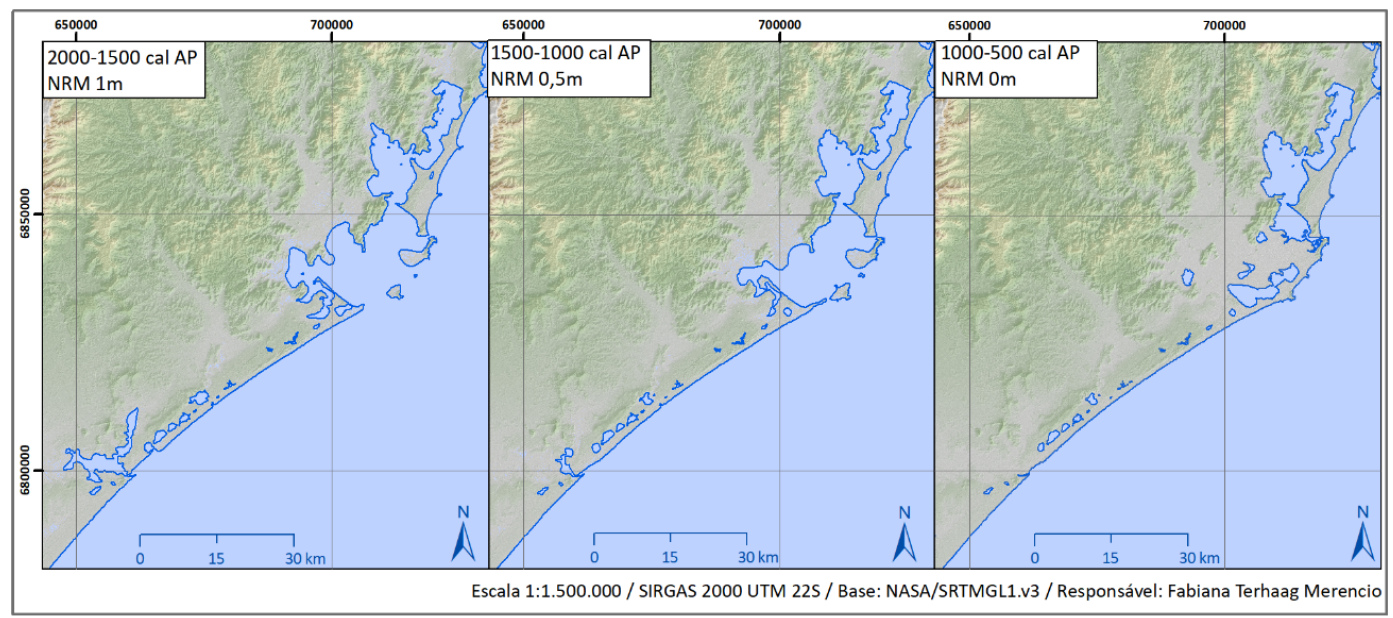

Fig. 2. Variações do nível relativo do mar entre 2000 a 500 anos cal AP no litoral sul de Santa Catarina. Fonte: elaborado pelos autores. 


\begin{tabular}{cccc}
\hline \multicolumn{2}{c}{ Declividade } & \multicolumn{2}{c}{$\begin{array}{c}\text { Hidrografia - Rank } \\
\text { order (Strahler 1957) }\end{array}$} \\
\hline $\begin{array}{c}\text { Valor } \\
\text { original }\end{array}$ & $\begin{array}{c}\text { Valor } \\
\text { reclassificado }\end{array}$ & $\begin{array}{c}\text { Valor } \\
\text { original }\end{array}$ & $\begin{array}{c}\text { Valor } \\
\text { reclassificado }\end{array}$ \\
\hline $1-5^{\circ}$ & 1 & $0-1$ & 1 \\
$5-10^{\circ}$ & 3 & $2-3$ & 3 \\
$10-15^{\circ}$ & 10 & $4-5$ & 10 \\
$15-20^{\circ}$ & 20 & $6-7$ & 20 \\
$20-30^{\circ}$ & 30 & 8 & 30 \\
$30-75^{\circ}$ & 50 & NoData & 0 \\
NoData & 1 & & \\
\hline
\end{tabular}

Tabela 2: Atribuição de custos na reclassificação nos rasters de declividade e hidrografia.

Fonte: elaborado pelos autores.

Na segunda etapa, o cálculo do custo acumulado da superfície, as superfícies de custo geradas para cada faixa cronológica na primeira etapa foram utilizadas para estimar o custo de deslocamento a partir de um ponto de origem. A ferramenta spatial analyst tools $>$ distance $>$ cost distance calcula dois tipos de arquivos necessários para o estágio seguinte: a distância a partir de um ponto de origem para todas as células do raster da superfície de custo (distance) e os valores das células vizinhas para identificar quais possuem os menores custos (backlink). Esse procedimento foi gerado individualmente para cada sítio, pois os arquivos produzidos apresentam resultados para cada ponto de origem.

A etapa final, o cálculo dos caminhos de menor custo, foi realizada por meio da ferramenta spatial analyst tools>distance >cost path, a partir dos arquivos obtidos no estágio anterior, resultando em um raster com valores dos caminhos para o destino, podendo ser um ponto ou vários. Neste estudo, foram estimados os caminhos a partir de um sítio para todos os demais ativos no mesmo período, com base nos arquivos de custo acumulado. Cada arquivo raster, referente aos caminhos previstos entre um sítio para os demais ativos na mesma faixa temporal, foi convertido para shapefile (conversion tools $>$ from raster>raster to polyline), e em seguida, todos os caminhos de cada faixa temporal foram agrupados em um único shapefile (data management $>$ general $>$ merge). Para melhor visualização dos caminhos gerados, foi criado um arquivo raster de densidade de sobreposição de linhas (spatial analyst tools>density>line density), considerando como parâmetros o tamanho da célula de $30 \mathrm{~m}$ e raio de $1 \mathrm{~km}$.

\section{Discussão dos resultados}

As informações obtidas para a construção do banco de dados georreferenciados e as datações disponíveis para a região (incluindo os dados desta pesquisa) possibilitaram verificar a dispersão espacial e temporal das diferentes ocupações relacionadas aos 42 sítios ativos entre 2000-500 anos cal AP (Fig. 3). As informações dos sítios ativos nesse período, como coordenadas UTM, datas ${ }^{14} \mathrm{C}$ e calibradas podem ser localizadas no apêndice. As datas foram calibradas no programa OxCal v.4.3 (Bronk Ramsey, 2014), com curvas apropriadas para cada tipo de material: curva atmosférica ShCall 13 para carvão, curva marinha Marine 13 para conchas com correção do delta $\mathrm{R}$ de $220 \pm 20$ (Eastoe et al. 2002) e curva mista para ossos humanos (Scheel-Ybert 2019). Conforme Gilson \& Lessa (2020: 9), as datas obtidas antes de 1970 tiveram os valores de ${ }^{13} \mathrm{C}$ corrigidos para que pudessem ser comparadas com as datações posteriores, utilizando-se a fórmula $\left(\sigma 13 \mathrm{C}^{*} \mathrm{E} \delta 13 \mathrm{C}\right)+\sigma \mathrm{DM}$, onde $\sigma 13 \mathrm{C}$ é desvio do ${ }^{13} \mathrm{C}, \mathrm{E} \delta^{13} \mathrm{C}$ ao espectro de flutuação do $\delta^{13} \mathrm{C}$, e $\sigma \mathrm{DM}$ ao desvio padrão da data medida. No caso da ausência dos dados, foram utilizados os valores máximos $\left(\sigma^{13} \mathrm{C}=16,4\right.$; e $\left.\mathrm{E} \delta^{13} \mathrm{C}=8\right)$. Por exemplo, a data publicada do Cabeçuda (4120 \pm 220 , Hannover 167) foi corrigida com os seguintes valores: $(16,4 * 8)+220=351$, resultando em uma variação de 351 em vez de 220 . 


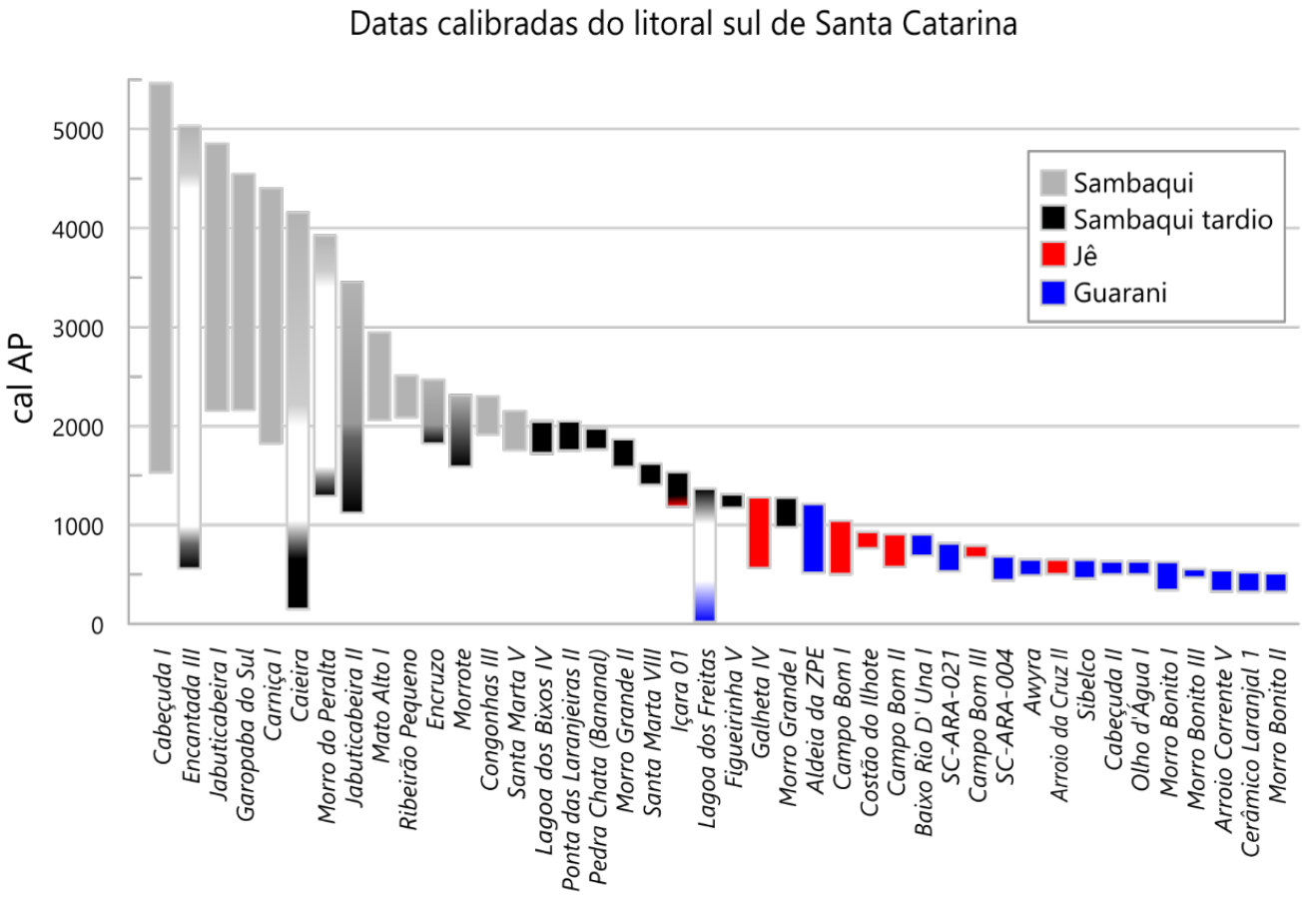

Fig. 3: Sítios ativos entre 2000 a 500 anos cal AP no litoral sul.

Fonte: elaborado pelos autores. Trabalhos consultados: Assunção (2010), Attorre (2015), Campos (2015), DeBlasis et al. (2007), DeBlasis, Farias \& Kneip (2014), DiGiusto (2017), Farias \& Kneip (2010), Farias et al. (2018), Giannini et al. (2010), Hurt (1974), Milheira (2010), Nishida (2007), Oliveira (2010), Saladino (2016), Santos, Pavei \& Campos (2016), Villagran (2012), esta pesquisa e dados do projeto Jê Landscapes of Southern Brazil.

Entre 2000-1500 anos cal AP, são registrados 20 sítios ativos, verificandose os primeiros indícios de alterações da composição estratigráfica, com a presença de sedimento escuro nas camadas superficiais de alguns sambaquis antigos, como em Jabuticabeira II, Morro do Peralta e Morrote. Nesse período, também são registrados os primeiros sambaquis tardios, que são sítios discretos na paisagem e, portanto, de baixa visibilidade. Exemplos de sambaquis tardios registrados nesse período são: Encruzo, Lagoa dos Bixos IV, Morro Grande II, Pedra Chata, Ponta das Laranjeiras II e Santa Marta VIII. Os sítios estão localizados majoritariamente no entorno da região lagunar (nas porções interna e externa) e em menor número na porção sul da área de pesquisa, próximos de pequenos lagos.
Os modelos de mobilidade estimados entre os sítios ativos nesse período apontam que as diferentes ocupações muito possivelmente integravam extensas redes de interação. Por exemplo, os caminhos estimados entre os sítios localizados no setor externo da paleolaguna como Santa Marta IV, V, VIII e Carniça I e os sambaquis tardios na porção sul - Içara 01 e Morro Grande II - passam próximos ao sambaquis Encantada III e Garopaba do Sul, situados na parte central da área de pesquisa. A mesma situação foi constatada nos caminhos previstos a partir do Jabuticabeira II, Pedra Chata, Ponta das Laranjeiras II e Encruzo, com destino ao Içara 01, e que também passam próximos do Morro Grande II (Fig. 4).

Em relação à funcionalidade, notaram-se certos padrões de implantação, com o registro de sítios funerários preferencialmente às 
margens ou próximos da paleolaguna central, ocupando distintos compartimentos geológicogeomorfológico (Giannini et al. 2010): em costões rochosos, como Caieira, Encruzo e Morro do Peralta; em paleotômbolos, como Cabeçuda I, Santa Marta V e VIII; em paleopontais de retrobarreira, como Carniça I; em morros testemunhos, como o Jabuticabeira II; e em terrenos arenosos planos do sistema barra-barreira, como o Garopaba do Sul. Além da paleolaguna central, outras áreas na porção sul passaram a apresentar uso funerário, como o Içara 01, localizado próximo de pequenos lagos (Fig. 4). Os demais sítios não apresentam, até o momento, elementos que apontem que se tratava de espaços funerários ou de habitação, devido à baixa variabilidade de vestígios e atividades registradas. No entanto, como enfatiza Villagran (2012), os demais sambaquis, e até mesmo sambaquis tardios, são resultado de processos construtivos intencionais, e, desse modo, podem ser interpretados como áreas de congregação social ou marcadores territoriais.

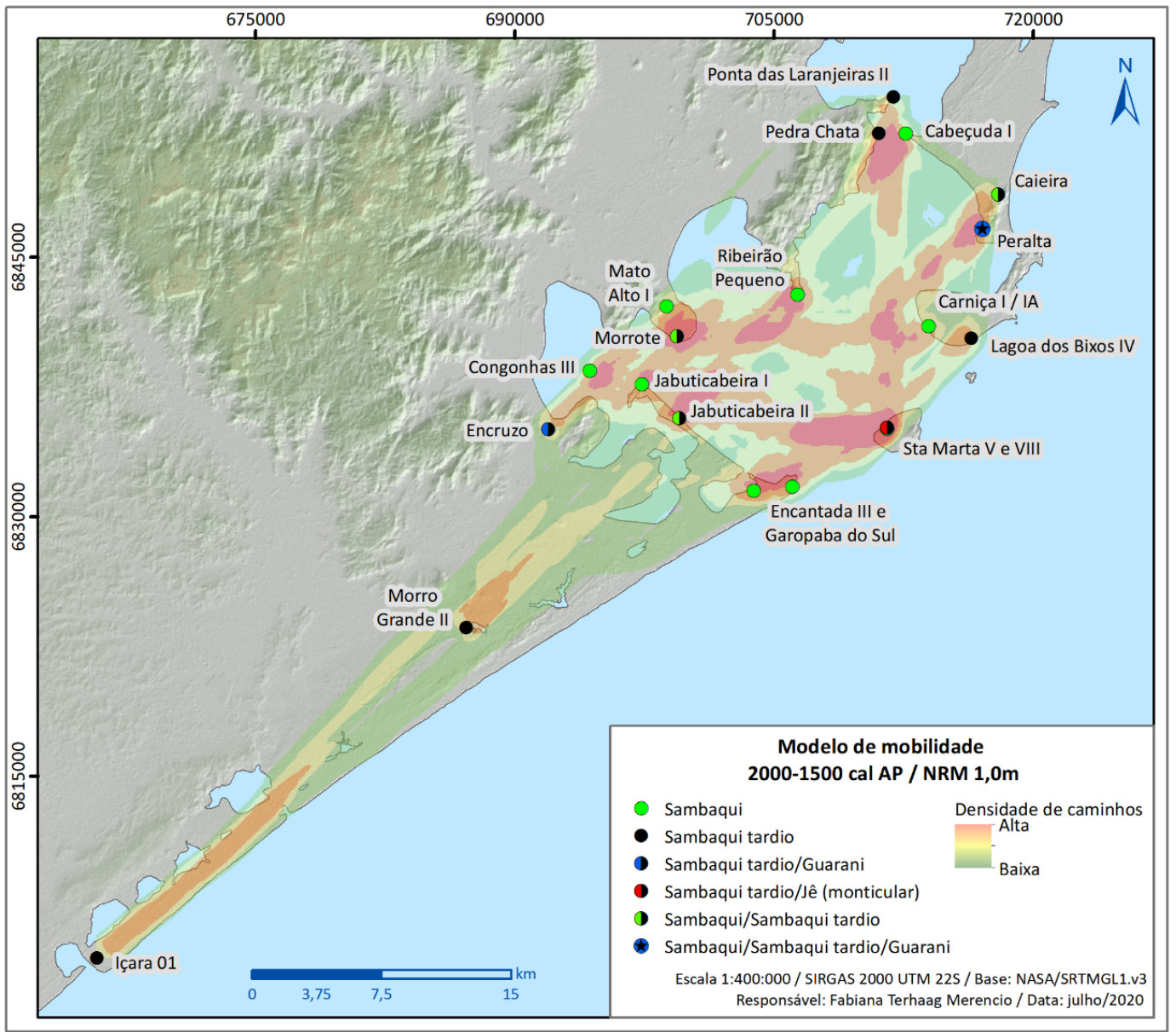

Fig. 4: Modelo de mobilidade entre sítios ativos no período entre 2000-1500 anos cal AP. Fonte: elaborado pelos autores.

Os dados do período entre 1500-1000 anos cal AP indicam a presença de 16 sítios ativos, com maior número de sambaquis tardios e primeiros registros da cerâmica Itararé-Taquara, 
Análises de mobilidade no litoral sul de Santa Catarina entre 2000-500 anos cal AP

R. Museu Arq. Etn., 36: 59-94, 2021.

tanto em sítios monticulares como em sítios conchíferos (Fig. 5), verificando-se, assim, uma maior intensidade dos processos de mudança e continuidade. A dispersão espacial dos sítios indica alterações nas características de implantação, com maior registro de sambaquis tardios na porção sul da área de pesquisa, localizados próximos de pequenas lagoas, como Içara 01, Lagoa dos Freitas, Morro Grande I e II e o Figueirinha V que possuem datas associadas a esse período. Contudo, outros sítios que possuem características semelhantes são registrados na mesma área, como o Arroio da Cruz de Dentro e Arroio da Cruz II, mas que não possuem datações. Com relação aos sítios funerários, há manutenção dos locais ativos no período anterior, como Jabuticabeira II, Içara 01, Santa Marta VIII e Morro do Peralta, situados próximos da paleolaguna, em paleotômbolos e em costões rochosos. O Galheta IV, sítio monticular funerário com evidências mais antigas de cerâmica ItararéTaquara no litoral sul, e ativo nesse período, também apresenta aspectos de continuidade, como a manutenção da implantação na paisagem, verificada em outros sítios funerários, concomitante a elementos de mudança, observados na presença de cerâmica ItararéTaquara e alterações na estratigrafia (DeBlasis, Farias \& Kneip 2014).

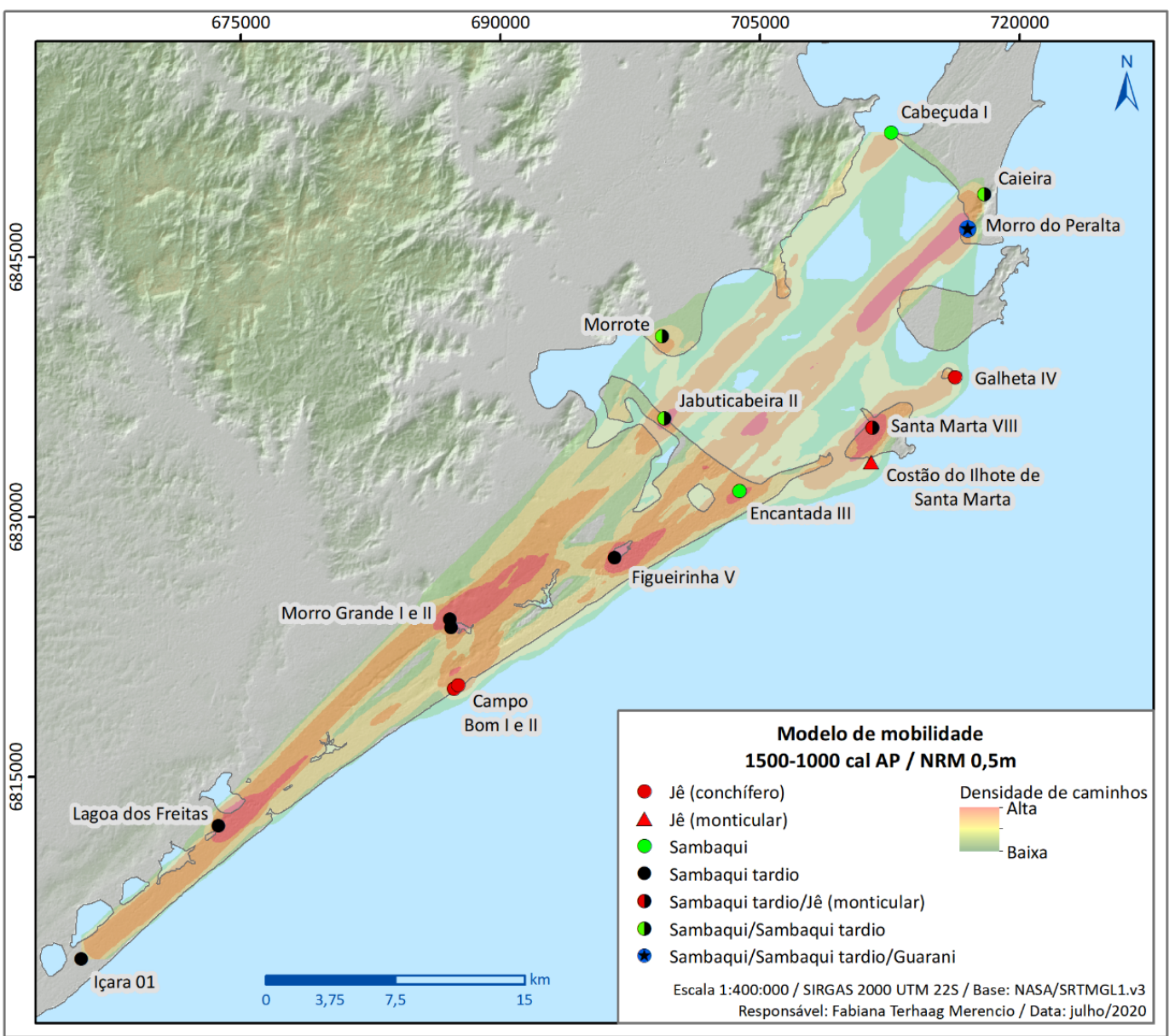

Fig. 5: Modelo de mobilidade entre sítios ativos no período entre 1500-1000 anos cal AP. Fonte: elaborado pelos autores. 
Os modelos de mobilidade gerados para essa faixa apontam para a presença de uma rede interligando os sambaquis tardios e sítios monticulares/conchíferos com cerâmica ItararéTaquara. Isso é verificado pela sobreposição de caminhos e pelo fato de, por exemplo, os caminhos entre Içara 01 e Galheta IV passarem próximos aos demais sambaquis tardios ativos, como Lagoa dos Freitas, Morro Grande I, Figueirinha V e Santa Marta VIII. A mesma situação foi notada no modelo de mobilidade estimado entre Içara 01 e Jabuticabeira II que perpassa o Lagoa dos Freitas e Morro Grande I. Interessante ressaltar que não há evidências de sepultamentos nos sambaquis tardios registrados na parte central: Lagoa dos Freitas, Morro Grande I e II, e Figueirinha V.

As mudanças são mais intensas depois de 1000 anos cal AP, com redução dos sambaquis tardios ativos (somente Morro Grande I) e aumento dos sítios guaranis, que passam a ocupar o entorno da região lagunar. Apesar disso, na linha da costa sul da área de pesquisa, foi registrada uma concentração de sítios conchíferos com cerâmica ItararéTaquara, ativos a partir de 800 anos cal AP (Arroio da Cruz I e Campo Bom I, II e III) (Farias et al. 2018; DeBlasis et al. 2018). Com relação aos sítios funerários, verifica-se ainda a manutenção na paisagem, com a implantação de sítios monticulares com cerâmica ItararéTaquara em áreas de afloramentos de embasamento cristalino, como no Costão do Ilhote de Santa Marta e Galheta IV. Em suma, nesse período mais tardio, os sítios com elementos Itararé-Taquara estariam restritos à faixa litorânea, em um território circunscrito pela ocupação guarani próxima das lagoas, e com idades a partir de 600 anos cal AP.

Os caminhos de menor custo foram calculados apenas entre sambaquis tardios, sambaquis e sítios com cerâmica ItararéTaquara, excluindo-se os sítios guarani. Dentre as categorias selecionadas, constatam-se nove sítios ativos: Arroio da Cruz I, Caieira, Campo Bom I, II e III, Costão do Ilhote de Santa Marta, Encantada III, Galheta IV e Morro Grande I (Fig. 6). O Encantada III é um sambaqui do tipo padrão estratigráfico núcleo quartzo-arenoso (Villagran 2012), apresentando feição monticular e estratigrafia composta por uma camada de sedimento escuro. Nas datações realizadas nesse sítio, foi obtida uma data de 721-560 anos cal AP (740 \pm 40 , Beta 189712) nos níveis iniciais, e que foi associada por Peixoto (2008) a um episódio de queima posterior à ocupação do sítio. Apesar disso, optou-se por incluir esse sítio na análise de mobilidade do período entre 1000-500 anos cal AP para verificar se havia alguma correspondência nos caminhos. Os resultados obtidos indicam a presença de um faixa de deslocamento preferencial na linha da costa, incluindo a área do Encantada III. Além disso, os deslocamentos estimados interligando os sítios localizados ao sul da área com o sambaqui Caieira, situado na margem oposta da desembocadura, passam próximos dos sítios guaranis ativos nessa faixa cronológica, como Sibelco e Morro Bonito I, II e III, que representam o início da ocupação guarani na área do estudo.

Os modelos de mobilidade apresentam, em suma, as possibilidades de deslocamento de menor custo, considerando as características do terreno e a presença de cursos hídricos. Para estimar o tempo de deslocamento, calculou-se a distância anisotrópica por meio da função de Tobler (1993) (Tobler's Hiking Function), que estima esse dado a partir da declividade: quanto maior o ângulo de declividade do terreno, maior será o custo de deslocamento, tanto em termos de energia quanto de tempo. Esse tipo de análise apresenta melhores resultados em comparação à distância euclidiana, tendo em vista que a última calcula a distância a partir de uma superfície plana (isotrópica).

A função de Tobler foi inserida no ArcGIS, a partir de uma planilha personalizada com os dados de fator vertical, responsável por estimar os custos de deslocamento entre as células do arquivo de declividade e a elevação, elaborada por Tripcevich $(2009)^{10}$. Para o cálculo da distância anisotrópica, foram seguidos os

10 Disponível em: 〈https://bit.ly/38qaRhB $>$. Acesso em: 09/03/2020. A tabela de fator vertical utiliza a seguinte fórmula: Metros por hora $=0.000166666 *(\operatorname{Exp}(3.5 *$ $($ Abs $(\operatorname{Tan}($ Radians $($ slope deg $))+0.05))))$. 
Análises de mobilidade no litoral sul de Santa Catarina entre 2000-500 anos cal AP

R. Museu Arq. Etn., 36: 59-94, 2021.

procedimentos descritos por Yanchar (2013), considerando-se um deslocamento de $4 \mathrm{~km} / \mathrm{h}$ em terreno plano, estimado a partir de estudos de Aldenderfer (1998) com populações andinas. O cálculo do tempo de deslocamento em horas a partir do ponto de origem foi realizado por meio da ferramenta path distance (spatial analyst tools $>$ distance), na qual foram inseridos os seguintes parâmetros: (1) input raster (ponto de origem: vetor do sítio); (2) output distance raster (aniso1hr); (3) input cost raster (declividade em graus); (4) output backlink raster (back1hr); (5) Vertical factors parameters $>$ input vertical raster (DEM); e (6) Vertical factor>table: tabela com os dados da função de Tobler. Para melhor visualização dos resultados, foram extraídas linhas de contorno com intervalos de duas horas a partir do raster gerado no procedimento anterior (spatial analyst tools $>$ surface analysis>contour).

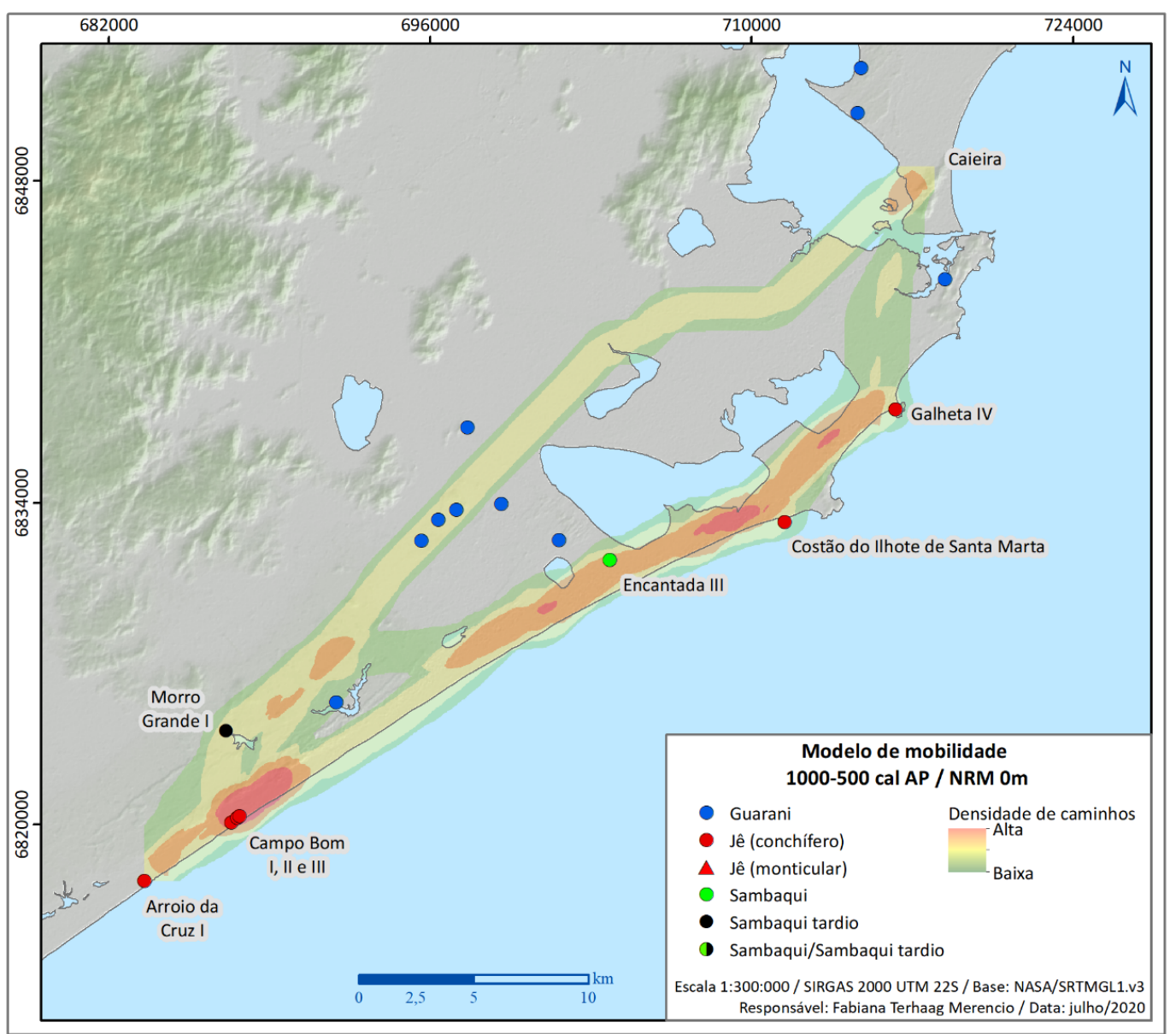

Fig. 6: Modelo de mobilidade entre sítios ativos no período entre 1000-500 anos cal AP.

Fonte: elaborado pelos autores.

Para esta pesquisa, foram geradas curvas anisotrópicas, tendo como ponto central a região da lagoa Bonita, área de registro dos sambaquis tardios Morro
Grande I e II, escavados recentemente pelo projeto Jê Landscape e focos da pesquisa de doutorado da autora Fabiana Merencio (Fig. 7). Os caminhos estimados a partir de 
ambos os sítios possuem tempo estimado de quatro a seis horas para chegar aos demais sítios ativos no entorno, localizados tanto na região lagunar central como na porção sul, correspondendo a um dia de caminhada. Os resultados das análises anisotrópicas indicam que os sítios ativos em cada faixa temporal, possivelmente, integravam um mesmo território e tinham algum tipo de nível de interação entre as diferentes ocupações registradas. No entanto, ressalta-se que os cálculos de curvas anisotrópicas foram realizados de forma exploratória para verificar as relações entre os sítios ativos em um mesmo período na região, sendo fundamental aprofundar os estudos na porção sul da área.

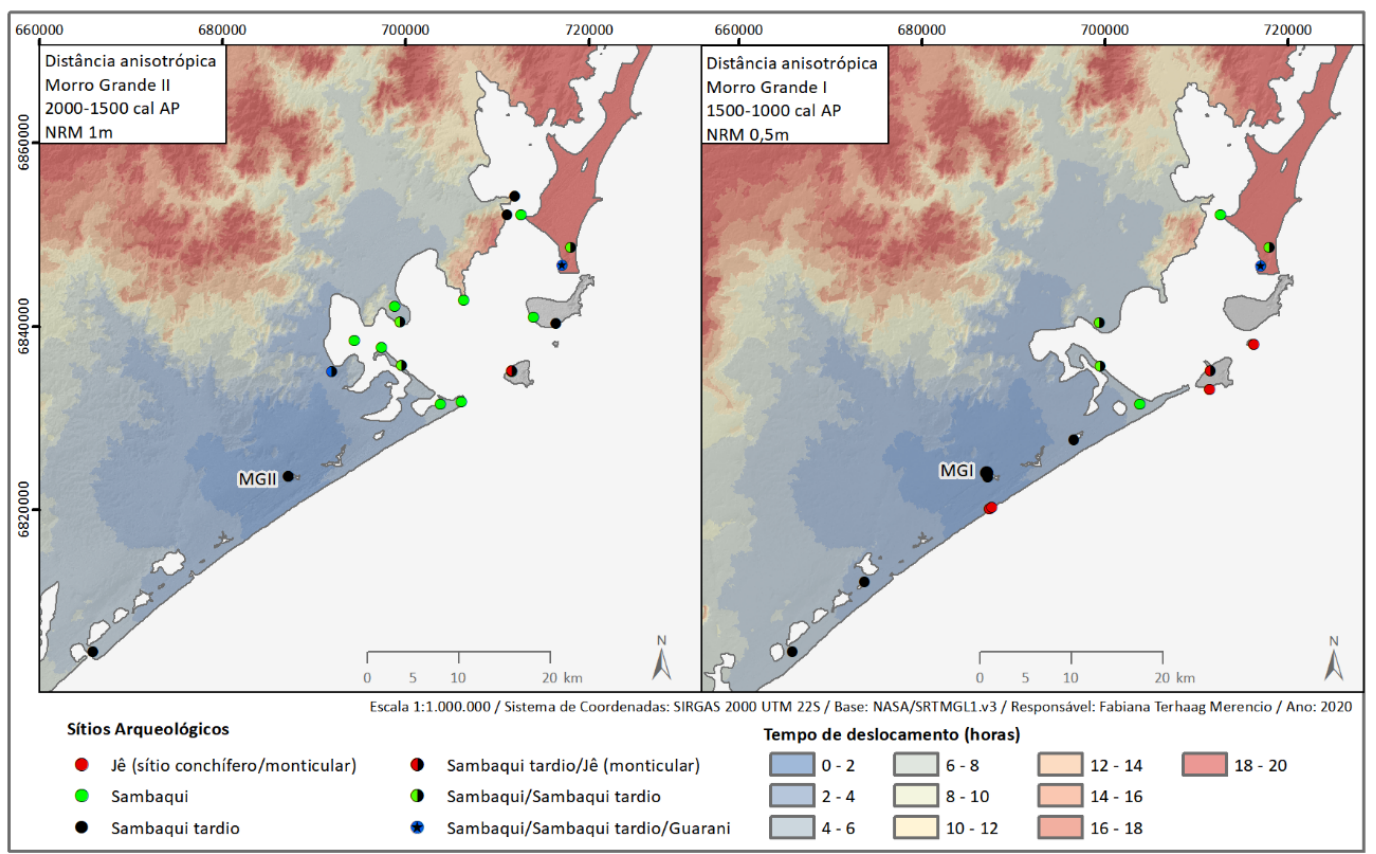

Fig. 7: Tempo de deslocamento estimado a partir de Morro Grande I e II (1500-1000 anos cal AP).

Fonte: elaborado pelos autores.

\section{Avaliação dos modelos de mobilidade}

$\mathrm{Na}$ etapa de levantamento extensivo, foram realizados caminhamentos nas porções sul e norte da área de pesquisa no período entre 26 de fevereiro a 02 de março de 2019. No extremo sul, na região de Morro Grande/ Torneiro, foi registrada a maior densidade de sambaquis tardios, além de esparsos sítios com cerâmica Itararé-Taquara nas dunas próximas às praias. Na porção norte, há relatos de sítios com cerâmica nas dunas de Itapirubá (Piazza 1966; Farias \& Kneip 2010). Para selecionar as áreas de prospecção, foram consideradas as características de implantação de sítios com cerâmica ItararéTaquara, registrados na região e áreas próximas dos caminhos de mobilidades, estimados entre os sítios ativos no período de 2000-500 anos cal AP. Foram verificados: (1) os cordões de dunas próximos às praias e cursos d'água; e (2) áreas interioranas do litoral, com presença de dunas estabilizadas e uso agrícola/mineração. Como resultado do levantamento extensivo, foram relocalizados três sítios arqueológicos registrados em pesquisas prévias, mas cuja posição geográfica era desconhecida até então: um sambaqui 
tardio na porção sul (Olho d'Água, UTM 22 $\mathrm{J}$ 680190/6818587), e os demais no extremo norte, sendo um sambaqui e um sambaqui com cerâmica guarani, que correspondem aos sítios Itapirubá I e II (UTM 22 J 723733/6864038 e 723520/6864015), registrados por Piazza (1966)

e com relato de cerâmica.

O sambaqui tardio Olho d'Água, registrado por Rohr $(1969,1984)$, está localizado a $20 \mathrm{~m}$ de uma estrada vicinal e $560 \mathrm{~m}$ do acesso à rodovia JAU-508, na localidade de Arroio da Cruz, no município de Jaguaruna (Fig. 8A). Assim como observado nos demais sambaquis tardios escavados por esta pesquisa, não é um sítio que se destaca na paisagem (Fig. 8B), pois não apresenta feição monticular, e é identificado a partir da presença de fragmentos de bivalves Donax hanleyanus (moçambique) e Amarilladesma mactroides (marisco branco) em meio a sedimento escuro, vestígios de fauna, em especial peixes, fragmentos de artefatos líticos e marcas de queima local observadas em conchas, ossos de mamíferos e sementes carbonizadas (Fig. 8C). Os vestígios estão dispersos em uma área principal de $100 \times 60 \mathrm{~m}$, com registro de uma concentração secundária de material no leito da estrada vicinal, distante cerca de $130 \mathrm{~m}$ da área do sítio. $\mathrm{O}$ local foi inspecionado por estar próximo ao caminho estimado a partir de Içara 01 para os demais sítios ativos entre 2000-1500 anos cal AP (Fig. 8A).
Os sambaquis Itapirubá I e II estão localizados na área de dunas de Itapirubá norte, distante cerca de $800 \mathrm{~m}$ da faixa da praia, e são conhecidos pelos moradores do entorno. A distância entre um sítio e outro é de $130 \mathrm{~m}$ e entre ambos perpassa o caminho de mobilidade estimado a partir do Arroio da Cruz I para os sítios ativos entre 1000. 500 anos cal AP, considerando somente o deslocamento por terra (Fig. 9). Ambos estão implantados sobre dunas que se destacam na paisagem e apresentam fragmentos de Anomalocardia flexuosa (berbigão), além de demais vestígios de fauna em superfície. $\mathrm{O}$ Itapirubá I tem maiores dimensões, com cerca de $150 \times 70 \times 5 \mathrm{~m}$. Os vestígios de fauna são observados no entorno e sobre a duna na qual o sítio está implantado. Além dos vestígios de fauna, foram identificados fragmentos de artefatos líticos dispersos e em pouca densidade. Contudo, isso se deve ao fato de esse sítio apresentar uma densa cobertura vegetal, o que possibilitou o acesso a apenas algumas porções do sítio. O Itapirubá II possui dimensões aproximadas de $40 \times 35 \times 2 \mathrm{~m}$ e está localizado em uma duna com pouca cobertura vegetal, estando, portanto, exposto à maior ação do vento e a atividades antrópicas, como o ciclismo. Pelo fato de ter pouca vegetação, destaca-se na paisagem e na imagem de satélite como uma mancha branca (em decorrência da grande quantidade de conchas). Em sua superfície, foi registrado um fragmento de cerâmica guarani. 

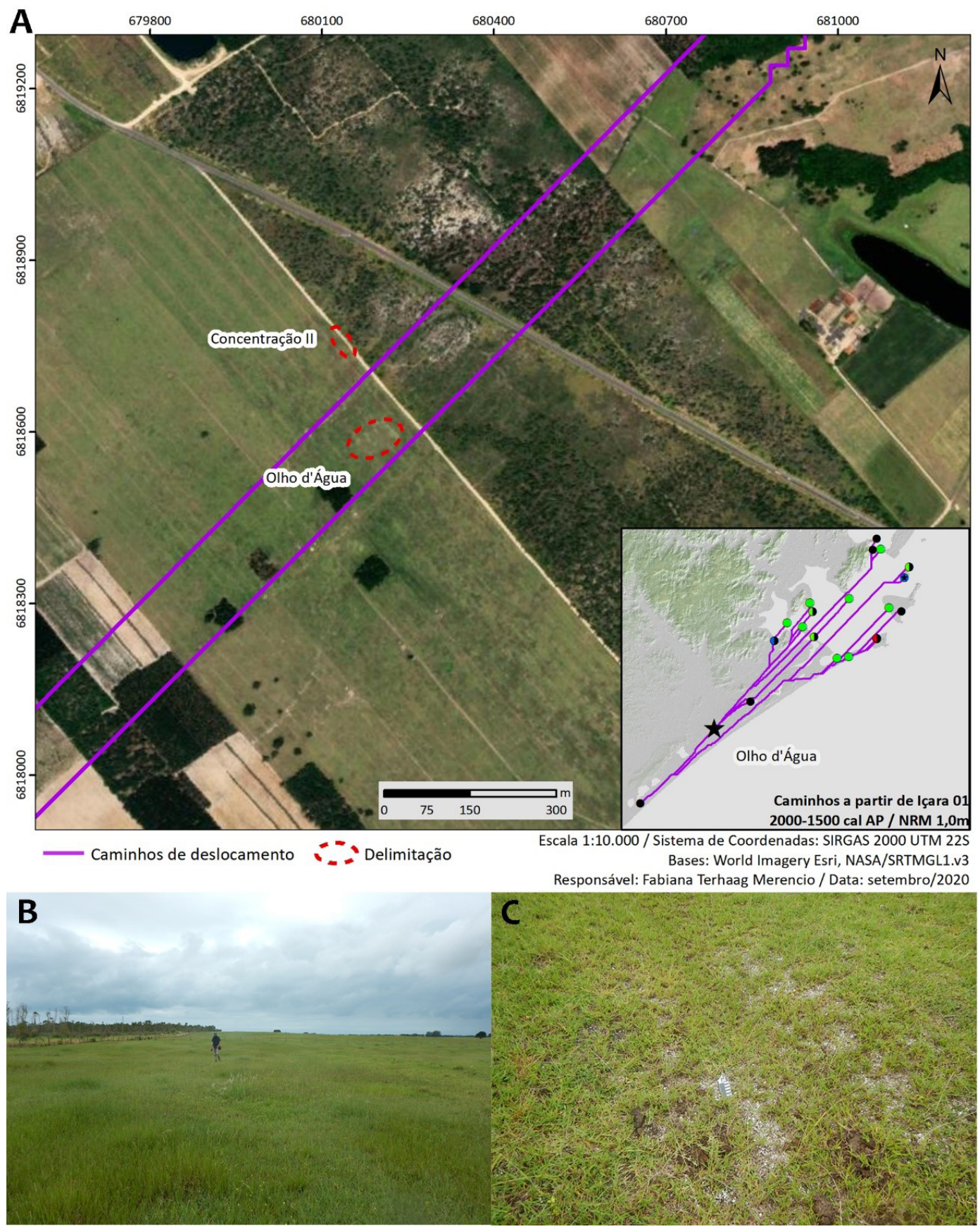

Fig. 8A: Localização do sítio Olho d'Água, com indicação dos caminhos de mobilidade a partir de Içara 01.

Fig. 8B: Implantação do sítio na paisagem.

Fig. 8C: Concentração de conchas em superfície.

Fonte: Fig. 8A elaborado pelos autores, Fig. 8B e 8C são fotos da autora, 2019. 
Análises de mobilidade no litoral sul de Santa Catarina entre 2000-500 anos cal AP

R. Museu Arq. Etn., 36: 59-94, 2021.
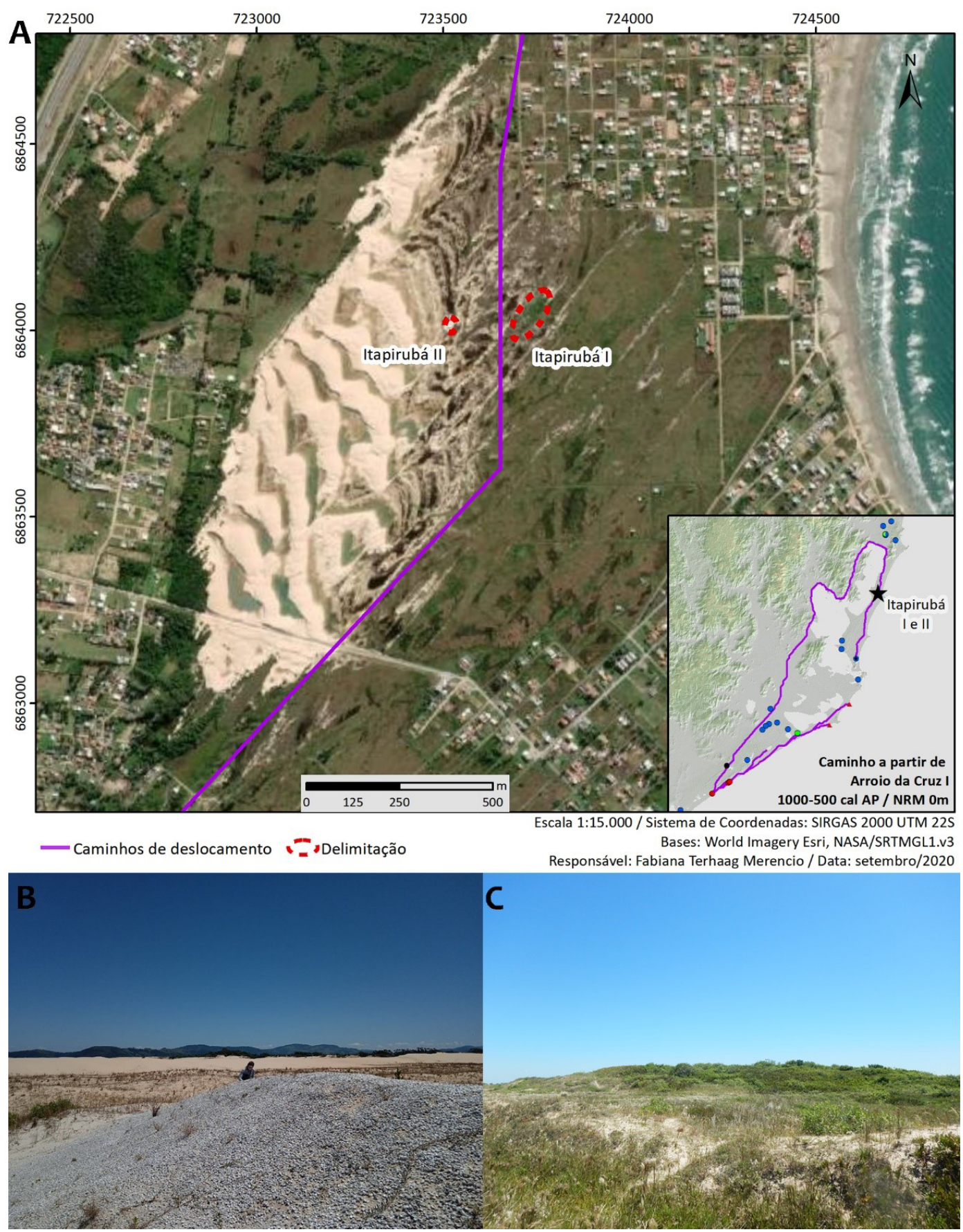

Fig. 9A. Localização dos sítios Itapirubá I e II com indicação dos caminhos de mobilidade a partir de Arroio da Cruz I (deslocamento somente por terra).

Fig. 9B. Sambaqui Itapirubá II, com destaque na paisagem.

Fig. 9C. Implantação na paisagem, sítio Itapirubá I.

Fonte: Fig. 9A elaborado pelos autores, Fig. 9B e 9C fotos da autora, 2019. 


\section{Conclusão}

No período de declínio de construção de sambaquis, entre 2000 a 1000 anos cal AP, são registradas maior variabilidade de ocupações relacionadas às mudanças nos processos construtivos dos sambaquis e ao aumento do número de sambaquis tardios; a partir de 1500 anos cal AP, passam a ser registrados esparsos sítios com cerâmica Itararé-Taquara, e, posteriormente, uma densa ocupação guarani a partir de 600 anos cal AP (Assunção 2010; Giannini et al. 2010; Milheira 2010; DeBlasis, Farias \& Kneip 2014). Quanto à distribuição dos sítios na paisagem, os dados apontam para a manutenção de padrões de implantação associados a determinadas categorias de sítios, em especial sítios funerários, concomitantemente ao registro de ocupações em áreas com características ambientais distintas.

Em relação às características de implantação de sambaquis tardios e sítios com cerâmica Itararé-Taquara, foram observadas até o momento distinções na seleção de áreas. Os sambaquis tardios, que representam uma ocupação com idades entre 2000 a 900 anos cal AP, estão localizados em uma faixa de dunas estáveis, próximos a lagos ou lagoas, e distantes cerca de dois a quatro quilômetros da faixa da praia. Na região entre o Morro Grande e Torneiro, esses sítios são discretos na paisagem e são identificados pela presença superficial de sedimento escuro associado a fragmentos de conchas (em especial de bivalves Donax hanleyanus e Amarilladesma mactroides, e gastrópodes Olivella sp. e Olivancillaria sp), além da fauna, sobretudo peixes.

Os sítios com cerâmica Itararé-Taquara estão, em sua maioria, em dunas próximas às praias e cursos d'água, na porção sul da área de pesquisa e nos costões cristalinos distribuídos no centro da poligonal. As características distintas de implantação desses sítios também refletem nas diferenças de uso e cronologia desses espaços: nos costões são registrados sítios monticulares funerários a partir de 1300 anos cal AP, enquanto nas dunas da porção sul, são registrados sítios conchíferos com elementos de ocupações temporárias a partir de 1000 anos cal AP.

As análises espaciais geradas auxiliaram na seleção de áreas de prospecção e contribuíram para a compreensão das mudanças no território de diferentes ocupações no litoral sul de Santa Catarina no período entre 2000 a 500 anos cal $\mathrm{AP}$, em que processos de interação são inferidos. Como enfatizado, é importante considerar que os caminhos de menor custo representam modelos idealizados, independentemente do número de critérios selecionados e qualidade dos dados, devendo ser estudados de forma exploratória. Além disso, na medida do possível, a verificação em campo dos modelos é altamente recomendada. Neste trabalho, a seleção de áreas verificadas no levantamento extensivo não foi condicionada somente aos locais indicados pelos modelos de mobilidade, sendo verificadas também as áreas que apresentavam características de implantação dos sítios conchíferos com cerâmica Itararé-Taquara. Como resultado, foram relocalizados três sítios registrados em pesquisas anteriores, mas cuja localização era até então desconhecida.

\section{Agradecimentos}

Nossos agradecimentos ao convênio FAPESP-RCUK/AHRC (processo $n^{\circ}$ 2012/51328-3) pelo apoio financeiro concedido ao projeto temático Jê Landscapes of Southern Brazil e à FAPESP (processo $n^{\circ}$ 2017/08131-8) pela bolsa de doutorado. Agradecemos a todos os integrantes do projeto Jê Landscapes e aos pesquisadores do Grupep-Unisul, Leia-UFSC, MAE-USP, IPATUNESC e Lepaarq-UFPEL que participaram voluntariamente das atividades de campo. E, por fim, agradecemos aos revisores, editores e aos professores membros da banca de doutorado (Dr. Andreas Kneip, Dr. Juliano Campos, Dra. Madu Gaspar e Dra. Ximena Villagran) pelos comentários e sugestões. 
Análises de mobilidade no litoral sul de Santa Catarina entre 2000-500 anos cal AP

R. Museu Arq. Etn., 36: 59-94, 2021.

MERENCIO, F.T.; DEBLASIS, P. Mobility analysis on the southern coast of Santa Catarina between 2000-500 cal BP. R. Museu Arq. Etn. 36: 59-94, 2021.

Abstract: The sambaqui (shellmound) has an ancient and long occupation in the southern coast of Santa Catarina, Brazil (ca. 7.5 to $1.5 \mathrm{kyBP}$ ). The final phase of this occupation (from ca. $2.0 \mathrm{kyBP}$ ) is marked by the decline in shell mound-building and changes in stratigraphy, with an increase of organic-rich sediment, in the superficial layers of early sambaquis and in discrete sites (late sambaquis), which presents elements of continuity and change compared to previous sambaquis. This period is associated with environmental re-shaping of the coastal landscape throughout late Holocene and with cultural processes such as the gradual contact between local sambaqui groups and southern Je people from the hinterland. The intensification of this contact is registered by the presence of Itararé-Taquara ceramics in fishmounds and shellmiddens (ca. 1.3 to $0.5 \mathrm{kyBP}$ ). This paper shows the spatial and temporal dispersion data of active sites between ca. 2.0 to $0.5 \mathrm{kyBP}$ on the south coast of Santa Catarina, by multi-criteria cost surface analysis (least cost path) between late sambaquis and Itararé-Taquara ceramic sites, investigating the territory organization and possible relations among different occupations in this period.

Keywords: Coastal archaeology; Late shellmound; Southern Jê; Mobility analysis; Least cost path.

\section{Referências bibliográficas}

ANA. 2017. Base Hidrográfica Ottocodificada Multiescalas. Disponível em: <https://bit.ly/ 3bzXGvz>. Acesso em: 15/07/2020.

Aldenderfer, M.S. (Ed). 1998. Montane Foragers: Asana and the south-central Andean archaic. University of Iowa Press, Iowa.

Ames, K.M. 2002. Going by boat: the forager-collector continuum at sea. In: Fitzhugh, B., Habu, J. (Eds.). Beyond foraging and collecting evolutionary change in hunter-gatherer settlement systems. Kluwer Academic; Plenum Publisher, New York, 19-52.

Angulo, R.J. et al. 1999. Relative sea-level changes in the last 5500 years in southern Brazil (LagunaImbituba region, Santa Catarina State) based on vermetid 14C ages. Marine Geology 159: 323-339.

Angulo, R.J.; Lessa, G.C.; Souza, M.C. 2006. A critical review of mid- to late-Holocene sea-level fluctuations on the eastern Brazilian coastline. Quaternary Science Reviews 25(5-6): 486-506.
Araujo, A.G.M. 2001. Teoria e método em arqueologia regional: um estudo de caso no Alto Paranapanema, estado de São Paulo. Tese de doutorado. Universidade de São Paulo, São Paulo.

Araujo, A.G.M. 2007. A tradição cerâmica ItararéTaquara: características, área de ocorrência e algumas hipóteses sobre a expansão dos grupos Jê no sudeste do Brasil. Revista de Arqueologia (20): 9-38.

Assunção, D. 2010. Sambaquis da paleolaguna de Santa Marta: em busca do contexto regional no litoral sul de Santa Catarina. Dissertação de mestrado. Universidade de São Paulo, São Paulo.

Attorre, T. 2015. Por uma arqueologia marginal: as ocupações peri-sambaquieiras no entorno do sambaqui da Figueirinha II, Jaguaruna-SC, examinadas através do radar de penetração de solo. Dissertação de mestrado. Universidade de São Paulo, São Paulo. 
Bandeira, D.R. 2004. Ceramistas pré-coloniais da Baía da Babitonga, SC: arqueologia e etnicidade. Tese de doutorado. Universidade Estadual de Campinas, Campinas.

Banning, E.B. 2002. Archaeological survey. Kluwer Academic; Plenum Publishers, New York.

Bastos, M.Q.R. 2009. Mobilidade humana na pré-história do litoral brasileiro: análise de isótopos instáveis de estrôncio no sambaqui do Forte Marechal Luz. Dissertação de mestrado. Fundação Oswaldo Cruz, Rio de Janeiro.

Beber, M.V. 2004. O sistema de assentamento dos grupos ceramistas do planalto sul-brasileiro: o caso da tradição Taquara/Itararé. Tese de doutorado. Universidade do Vale do Rio dos Sinos, São Leopoldo.

Beck, A. 1972. A variação do conteúdo cultural dos sambaquis: litoral de Santa Catarina. Tese de doutorado. Universidade de São Paulo, São Paulo.

Bell, T.; Lock, G.R. 2000. Topographic and cultural influences on walking the ridgeway in later prehistoric times. In: Lock, G.R. (Ed.) Beyond the map: archaeology and spatial technologies. IOS Press, Amsterdam, 85-100.

Bendazzoli, C. 2007. O processo de formação dos sambaquis: uma leitura estratigráfica do sítio Jabuticabeira II, SC. Dissertação de mestrado. Universidade de São Paulo, São Paulo.

Bitencourt, A.L.V.; Krauspenhar, P.M. 2006. Possible prehistoric anthropogenic effect on Araucaria angustifolia (Bert.) O. Kuntze expansion during the late Holocene. Revista Brasileira de Paleontologia 9(1): 109-116.

Borba, T.M. 1908. Actualidade indígena (Paraná, Brazil). Impressora Paranaense, Curitiba.

Brantings, S. 2012. Seven solutions for seven problems with least cost pathways. In: White, D.A.; SurfaceEvans, S.L. (Eds.). Least cost analysis of social landscapes. University of Utah Press, Salt Lake City, 209-224.
Bronk Ramsey, C. (2014). OxCal Program, Version 4.3.

Campos, J.B. 2015. Arqueologia entre rios e gestão integrada do território no extremo sul de Santa Catarina Brasil. Tese de doutorado. Universidade do Trás-os-Montes e Alto Douro, Vila Real.

Cardoso, J.M. 2019. O sítio costeiro Galheta IV: uma perspectiva zooarqueológica. Dissertação de mestrado. Universidade de São Paulo, São Paulo.

Centro Nacional de Arqueologia. 2019. Sítios Arqueológicos Georreferenciados. Disponível em: $<$ https://bit.ly/30whIAW>. Acesso em: 09/03/2020.

Colonese, A.C. et al. 2014. Long-term resilience of late Holocene coastal subsistence system in southeastern South America. PLoS ONE 9(4): 1-13.

Conolly, J.; Lake, M. 2006. Geographical information systems in archaeology. Cambridge University Press, Cambridge.

Coppock, J.T.; Rhind, D.W. 1991. The history of GIS. In: Maguire, D.J.; Goodchild, M.F.; Rhind, D.W. (Eds.). Geographical information systems: principles and Applications. Longman Group, Harlow, 1: 21-43.

Corrêa, A.A. 2009. Tetama nas matas mineiras: sítios Tupi na microrregião de Juiz de Fora-MG. Dissertação de mestrado. Universidade de São Paulo, São Paulo.

Corteletti, R. 2012. Projeto arqueológico Alto Canoas - Paraca: um estudo da presença Jê no planalto catarinense. Tese de doutorado. Universidade de São Paulo, São Paulo.

Corteletti, R. 2013. Uma estratigrafia da paisagem proto-Jê meridional: um estudo de caso em Urubici, SC. Revista Tempos Acadêmicos (11): 97-116.

Corteletti, R. et al. 2015. Revisiting the economy and mobility of southern proto-Jê (TaquaraItararé) groups in the southern Brazilian highlands: starch grain and phytoliths analyses from the Bonin site, Urubici, Brazil. Journal of Archaeological Science 58: 46-61. 
Análises de mobilidade no litoral sul de Santa Catarina entre 2000-500 anos cal AP

R. Museu Arq. Etn., 36: 59-94, 2021.

D’Ávila, L. 2017. Caminhos e lugares: modelos de mobilidade e sistema de assentamento entre os proto-Jê meridionais na região de Campo Belo do Sul, SC. Dissertação de mestrado. Universidade Federal de Pelotas, Pelotas.

DeBlasis, P.; Gaspar, M. 2009. Os sambaquis do sul catarinense: retrospectiva e perspectivas de dez anos de pesquisas. Especiaria: Cadernos de Ciências Humanas 11-12(20-21): 83-126.

DeBlasis, P.; Farias, D.S.; Kneip, A. 2014. Velhas tradições e gente nova no pedaço: perspectivas longevas de arquitetura funerária na paisagem do litoral sul catarinense. Revista do Museu de Arqueologia e Etnologia (24): 109-136.

DeBlasis, P. et al. 2007. Sambaquis e Paisagem: dinâmica natura e arqueologia regional no litoral do sul do Brasil. Arqueología Suramericana 3(1): 29-61.

DeBlasis, P. et al. 2018. Jê landscapes of Southern Brazil. (Relatório final). FAPESP-RCUK/AHRC (2012/51328-3), São Paulo.

DeMasi, M.A.N. 2001. Pescadores coletores da costa sul do Brasil. Pesquisas, Antropologia (57).

Di Giusto, M.N. 2017. Os sambaquieiros e os outros: estresse e estilos de vida na perspectiva da longa duração: o caso do litoral sul de Santa Catarina. Dissertação de mestrado. Universidade de São Paulo, São Paulo.

Eastoe, C. et al. 2002. Reservoir corrections for marine samples from the South Atlantic Coast, Santa Catarina State, Brazil. Radiocarbon 44(1): 145-148.

EPAGRI/CIRAM. 2007. Mapa digital das Unidades Hidrográficas do Estado de Santa Catarina (shapefile). Disponível em: <https://bit. ly/3n9UJ8b >. Acesso em: 15/07/2020.

Farias, D.S.E.; DeBlasis, P. 2014. Programa de salvamento arqueológico e educação patrimonial na área de duplicação da BR-101 trecho Ponte de Cabeçuda, Laguna/SC. (Relatório final). Iphan (01510.000341/2007-72), Tubarão.
Farias, D.S.E.; Kneip, A. 2010. Panorama arqueológico de Santa Catarina. Editora Unisul, Palhoça.

Farias, D.S.E. et al. 2018. Salvamento Arqueológico e Educação Patrimonial na Área de Influência Indireta do Aeroporto Regional Sul Humberto Ghizzo Bortoluzzi, Município de Jaguaruna - SC. (Relatório final). Iphan (01510.900106/2017-74), Tubarão.

Figuti, L. 1993. O homem pré-histórico, o molusco e o sambaqui: considerações sobre a subsistência dos povos sambaquieiros. Revista do Museu de Arqueologia e Etnologia (3): 67-80.

Gakran, N. 2015. Elementos fundamentais da gramática Laklãnõ. Tese de doutorado. Universidade de Brasília, Brasília.

Gaspar, M.D. et al. 2007. Tratamento dos mortos entre os sambaquieiros, Tupinambá e Goitacá que ocuparam a Região dos Lagos, estado do Rio de Janeiro. Revista do Museu de Arqueologia e Etnologia (17): 169-189.

Gaspar, M.D. et al. 2008. Sambaqui (shell mound) societies of coastal Brazil. In: Silverman, H.; Isbell, W.H. (Eds.). Handbook of South American archaeology. Springer, New York, 319-337.

Geyh, M.A.; Schneekloth, H. 1964. Hannover radiocarbon measurements III.

Radiocarbon 6: 251-268.

Giannini, P.C.F. et al. 2010. Interações entre evolução sedimentar e ocupação humana pré-histórica na costa centro-sul de Santa Catarina, Brasil. Boletim do Museu Paraense Emílio Goeldi, Ciências Humanas 5(1): 105-128.

Gilson, S.-P.; Lessa, A. 2020. Ocupação tardia do litoral norte e central catarinense por grupos pescadores-caçadores-coletores: uma revisão crítica do contexto cronológico dos sítios rasos com presença de cerâmica. Revista de Arqueologia 33(1): 55-77.

Gustas, R.; Supernant, K. 2017. Least cost path analysis of early maritime movement on the 
Pacific Northwest coast. Journal of Archaeological Science 78: 40-56.

Hansel, F.A.; Schmitz, P.I. 2006. Classificação e interpretação dos resíduos orgânicos preservados em fragmentos de cerâmica arqueológica por cromatografia gasosa e cromatografia gasosa - espectrometria de massas. Pesquisas, Antropologia (63): 81-112.

Haynes, C.V.; Grey, D.C.; Long, A. 1971. Arizona radiocarbon dates VIII. Radiocarbon 13(1): 1-18.

Herzog, I. 2014. A review of case studies in archaeological least-cost analysis. Archeologia e Calcolatori XXV: 223-239.

Howey, M. 2007. Using multi-criteria cost surface analysis to explore past regional landscapes: a case study of ritual activity and social interaction in Michigan, AD 1200-1600. Journal of Archaeological Science 34(11): 1830-1846.

$\mathrm{Hu}$, D. 2012. Advancing theory? Landscape archaeology and geographical information systems. Papers from the Institute of Archaeology 21: 80-90.

Hubbe, M. et al. 2009. Postmarital Residence Practice in Southern Brazilian Coastal Groups: Continuity and Change. Latin American Antiquity 20(2): 267-278.

Hurt, W.R. 1974. The interrelationship between the natural environment and four sambaquis, coast of Santa Catarina, Brazil. Occasional papers and monographs. Indiana University Museum, Bloomington.

Iriarte, J.; Behling, H. 2007. The expansion of Araucária forest in the Southern Brazilian highlands during the last 4000 years and its implications of the Taquara/Itararé Tradition. Environment Archaeology 12(2): 115-127.

Iriarte, J. et al. 2014. Paisagens Jê meridionais: ecologia, história e poder numa paisagem transicional durante o holoceno tardio. Cadernos do Lepaarq 11(22): 240-253.
Iriarte, J. et al. 2016. Landscape dynamics in the La Plata Basin during the mid and late Holocene. Cadernos do Lepaarq 13(25): 268-302.

Klokler, D. et al. 2010. Juntos na costa: zooarqueologia e geoarqueologia de sambaquis do litoral sul catarinense. Revista do Museu de Arqueologia e Etnologia (20): 53-75.

Klokler, D.; Gaspar, M.; \& Scheel-Ybert, R. (2018). Why clam? Why clams? Shell Mound construction in Southern Brazil. Journal of Archaeological Science: Reports 20: 856-863.

Kneip, A. 2004. O povo da lagoa: uso do SIG para modelamento e simulação na área arqueológica do Camacho. Tese de doutorado. Universidade de São Paulo, São Paulo.

Kneip, A.; Farias, D.; DeBlasis, P. 2018. Longa duração e territorialidade da ocupação sambaquieira na laguna de Santa Marta, Santa Catarina. Revista de Arqueologia 31(1): 25-51.

Kneip, A.; Mello, A.A.S. 2018. Dinâmica da ocupação da região do camacho, litoral sul de Santa Catarina, a partir de 7500 anos até o presente. Revista Memorare 5(1): 248-263.

Kozlowski, H.S.; Corteletti, R. 2019. Paisagem de mobilidade Jê meridional do alto vale do Ribeira de Iguape. Arqueologia 22(1): 1-23.

Lessa, A. 2006. Reflexões preliminares sobre paleoepidemiologia da violência em grupos ceramistas litorâneos: (I) Sítio Praia da Tapera SC. Revista do Museu de Arqueologia e Etnologia (15-16): 199-207.

Lessa, A.; Scherer, L.Z. 2008. O outro lado do paraíso: novos dados e reflexões sobre violência entre pescadores-coletores pré-coloniais. Revista do Museu de Arqueologia e Etnologia (18): 89-100.

Li, X. et al. 2009. GIS Analysis of Global Impacts from Sea Level Rise. Photogrammetric Engineering \& Remote Sensing 75(7): 807-818. 
Análises de mobilidade no litoral sul de Santa Catarina entre 2000-500 anos cal AP

R. Museu Arq. Etn., 36: 59-94, 2021.

Lima, T.A. 2000. Em busca dos frutos do mar: os pescadores-coletores do litoral centro-sul do Brasil. Revista USP (44): 270-327.

Livingood, P. 2012. No crows made mounds: do cost-distance calculations of travel time improve our understanding of southern appalachian polity size? In: White, D.A.; Surface-Evans, S.L. (Eds.). Least cost analysis of social landscapes: archaeological case studies. University of Utah Press, Salt Lake City, 174-187.

Menezes, P.M L. 2009. Análise de fácies e proveniência sedimentar em sambaquis do litoral centro-sul de Santa Catarina. Dissertação de mestrado. Universidade de São Paulo, São Paulo.

Milheira, R.C. 2010. Arqueologia guarani no litoral sul-catarinense: história e território. Tese de doutorado. Universidade de São Paulo, São Paulo.

NASA JPL. 2013. NASA Shuttle Radar Topography Mission Global 1 arc second. NASA EOSDIS Land Processes DAAC. Disponível em: $<$ https://bit.ly/3pdVizk>. Acesso em: 15/07/2020.

Neves, W.A. 1988. Paleogenética dos Grupos PréHistóricos do Litoral Sul do Brasil (Paraná e Santa Catarina). Pesquisas, Antropologia (43): 9-178.

Nishida, P. 2007. A coisa ficou preta: estudo do processo de formação da terra preta do sítio arqueológico Jabuticabeira II. Tese de doutorado. Universidade de São Paulo, São Paulo.

Noelli, F.S. 1999. Repensando os rótulos e a história dos Jê no sul do Brasil a partir de uma interpretação interdisciplinar. Revista do Museu de Arqueologia e Etnologia (supl.3): 285-302.

Noelli, F.S. 2000. A ocupação humana na região sul do Brasil: arqueologia, debates e perspectivas 18722000. Revista USP (44): 218-269.

Noelli, F.S. 2005. Rethinking stereotypes and the history of research on Jê populations in South Brazil: an interdisciplinary point of view. In: Funari, P.; Zarankin, A.; Stovel, E. (Eds.). Global archaeological theory contextual voices and contemporary thoughts. Springer, New York, 167-190.

Noelli, F.S.; Souza, J.G. 2017. Novas perspectivas para a cartografia arqueológica Jê no Brasil meridional. Boletim do Museu Paraense Emílio Goeldi, Ciências Humanas 12(1): 57-84.

Okumura, M.M. 2008. Diversidade morfológica craniana, micro-evolução e ocupação préhistórica da costa brasileira. Pesquisas, Antropologia (66).

Oliveira, T.F. 2010. Estudo comparativo dos sambaquis Caipora, Lageado e Jaboticabeira I: interpretações acerca da mudança de material construtivo ao longo do tempo. Dissertação de mestrado. Universidade de São Paulo, São Paulo.

Oppitz, G. 2015. Coisas que mudam: os processos de mudança nos sítios conchíferos catarinenses e um olhar isotópico sobre o caso do sítio Armação do Sul, Florianópolis/SC. Dissertação de mestrado. Universidade de São Paulo, São Paulo.

Parellada, C.I. 2005. Estudo arqueológico no alto vale do rio Ribeira: área do gasoduto BolíviaBrasil, trecho X, Paraná. Tese de doutorado. Universidade de São Paulo, São Paulo.

Parellada, C.I. 2008. Tecnologia e estética da cerâmica Itararé-Taquara no Paraná: dados etno-históricos e o acervo do Museu Paranaense. Revista de Arqueologia 21(1): 97-111.

Peixoto, S.A. 2008. Pequenos aos montes: uma análise dos processos de formação dos sambaquis de pequeno porte do litoral sul de Santa Catarina. Dissertação de mestrado. Universidade Federal do Rio de Janeiro, Rio de Janeiro.

Piazza, W.F. 1966. Estudos de sambaquis (nota prévia). Imprensa Universitária UFSC, Florianópolis.

Prates, L.; Bonomo, M. 2017. Los ambientes acuáticos en arqueología. Arqueología 23(3): 11-33.

Prous, A. 1992. Arqueologia Brasileira. Editora UNB, Brasília. 
Redman, C.L. 1973. Multistage fieldwork and analytical techniques. American Antiquity 38(1): 61-79.

Reis, J.A. 2002. Arqueologia dos Buracos de Bugre: uma pré-história do Planalto Meridional. Educs, Caxias do Sul.

Riris, P.G.C. 2014. Exploring the spatial structure of pre-Columbian cultural landscapes in the Alto Paraná (Misiones province, Argentina). Tese de doutorado. University of Southampton, Southampton.

Rohr, J.A. 1969. Os sítios arqueológicos do município sul-catarinense de Jaguaruna. Pesquisas, Antropologia (22): 1-39.

Rohr, J.A. 1984. Sítios arqueológicos de Santa Catarina. Anais do Museu de Antropologia da UFSC 17: 77-168.

Rosa, R. 2005. Geotecnologias na Geografia aplicada. Revista do Departamento de Geografia 16: 81-90.

Saladino, A.A. 2016. Morte enfeitada: um olhar sobre as práticas mortuárias dos construtores do sambaqui Cabeçuda a partir de um sepultamento infantil. Dissertação de mestrado. Universidade Federal do Rio de Janeiro, Rio de Janeiro.

Saldanha, J.D.M. 2005. Paisagens, lugares e cultura material: uma arqueologia espacial nas terras altas do sul do Brasil. Dissertação de mestrado. Pontifícia Universidade Católica do Rio Grande do Sul, Porto Alegre.

Santos, J.; Milheira, R.G.; Campos, J.B. 2017. Entre rios, dunas, lagoas e o mar: arqueologia guarani no litoral sul de Santa Catarina. Revista de Arqueologia 30(1): 28-55.

Santos, M.C.P.; Pavei, D.D.; Campos, J.B. 2016. Arqueologia Entre Rios: do Urussanga ao Mampituba. Paleoambiente, cultura material e ocupação humana na paisagem litorânea do extremo sul catarinense entre 3500-200 anos AP. Cadernos do Ceom 29(45): 64-86.
Santos, M.C.P.; Pavei, D.D.; Campos, J.B. 2018. Sambaqui Lagoa dos Freitas, Santa Catarina: estratigrafia, antiguidade, arqueofauna, e cultura material. Revista Memorare 5(1): 157-196.

Scheel-Ybert, R. 2019. Calibração de datas radiocarbônicas em sítios costeiros. Revista de Arqueologia 32(2): 119-134.

Schiffer, M.B.; Sullivan, A.P.; Klinger, T.C. 1978. The design of archaeological surveys. World Archaeology 10(1): 1-28.

Schmitz, P.I. 1958. Paradeiros guaranis em Osório (Rio Grande do Sul). Pesquisas, Antropologia 2: 113-143.

Schmitz, P.I. 1988. As tradições ceramistas do planalto sul-brasileiro. Documentos (2): 75-139.

Schmitz, P.I.; Rogge, J.H. 2011. 107 'Casas subterrâneas' no início do povoamento Jê meridional em Santa Catarina: rincão dos Albinos. Revista do Museu de Arqueologia e Etnologia (21): 185-204.

Schmitz, P.I.; Rogge, J.H. 2013. Pesquisando a trajetória do Jê Meridional. Pesquisas, Antropologia (70): 7-33.

Schmitz, P.I. et al. 1999. Içara: um jazigo mortuário no litoral de Santa Catarina. Pesquisas, Antropologia (55).

Schmitz, P.I. et al. 2010. Casas subterrâneas no planalto de Santa Catarina: São José do Cerrito. Pesquisas, Antropologia (68): 7-78.

Schmitz, P.I. et al. 2013a. Rincão dos Albinos: um grande sítio Jê meridional. Pesquisas, Antropologia (70): 65-131.

Schmitz, P.I. et al. 2013b. Boa Parada, um lugar de casas subterrâneas, aterros-plataforma e 'danceiro'. Pesquisas, Antropologia (70): 133-195.

Schwengber, V.L. 2015. Resgate arqueológico em área de extração de areia na localidade de Sambaqui, Município de Imbituba-SC. (Relatório final). Iphan (01510.000603/2014-28), Tubarão. 
Análises de mobilidade no litoral sul de Santa Catarina entre 2000-500 anos cal AP

R. Museu Arq. Etn., 36: 59-94, 2021.

Silva, B.L.R. 2018. Sistema de assentamento proto-Jê meridional no alto rio Canoas. Dissertação de mestrado. Universidade de São Paulo, São Paulo.

Silva, S.B. et al. 1990. Escavações Arqueológicas do Pe. João Alfredo Rohr. O sítio arqueológico da Praia da Tapera: um assentamento ltararé e Tupiguarani. Pesquisas, Antropologia (45).

Souza, J.G. 2009. A cerâmica de tradição ItararéTaquara (RS/SC/PR) e a difusão das línguas Jê meridionais: uma reanálise dos dados. Trabalho de conclusão de curso. Universidade Federal do Rio Grande do Sul, Porto Alegre.

Souza, J.G. 2012. Paisagem ritual no planalto meridional brasileiro: complexos de aterros anelares e montículos funerários Jê do Sul em Pinhal da Serra, RS. Dissertação de mestrado. Universidade de São Paulo, São Paulo.

Souza, J.G.; Copé, S.M. 2011. Novas perspectivas sobre a arquitetura ritual do planalto meridional brasileiro: pesquisas recentes em Pinhal da Serra, RS. Revista de Arqueologia 23(2): 98-111.

Strahler, A.N. 1957. Quantitative analysis of watershed geomorphology. Transactions, American Geophysical Union 38(6): 913-920.

Tobler, W. 1993. Three presentations on geographical analysis and modeling technical. (Relatório técnico). NCGIA (TR-93-1), Regents. Disponível em: $<$ https://bit.ly/3lb9tnh>. Acesso em: 11/03/2021.

Tripcevich, N. 2009. Cost-distance analysis. Disponível em: <https://bit.ly/2U7fvc7>. Acesso em: 15/04/2018.

Urban, G. 1992. A história da cultura brasileira segundo as línguas nativas. In: Cunha, M.C. (Org.). História dos índios no Brasil. Companhia das Letras, São Paulo, 87-102.

Veiga, J. 2006. Aspectos fundamentais da cultura Kaingang. Editora Curt Nimuendajú, Campinas.

Villagran, X.S. 2008. Análise de arqueofácies na camada preta do sambaqui Jabuticabeira II.
Dissertação de mestrado. Universidade de São Paulo, São Paulo.

Villagran, X.S. 2012. Micromorfologia de Sítios Conchíferos da América do Sul. Arqueoestratigrafia e Processos de Formação de Sambaquis (Santa Catarina e Argentina). Tese de doutorado. Universidade de São Paulo, São Paulo.

Villagran, X.S. 2013. O que sabemos dos grupos construtores de sambaqui? Breve revisão da arqueologia da costa sudeste, dos primeiros sambaquis até a chegada da cerâmica Jê. Revista do Museu de Arqueologia e Etnologia (23): 139-154.

Villagran, X.S. et al. 2010. Lecturas estratigráficas: arquitectura funeraria y depositación de residuos en el sambaquí Jabuticabeira II. Latin American Antiquity 21(2): 195-216.

Wesolowski, V. 2007. Cáries, desgaste, cálculos dentários e micro-resíduos da dieta entre grupos pré-históricos do litoral norte de Santa Catarina: é possível comer amido e não ter cárie? Tese de doutorado. Fundação Osvaldo Cruz, Rio de Janeiro.

Wheatley, D.; Gillings, M. 2002. Spatial technology and archaeology: the archaeological applications of GIS. Taylor \& Francis, London.

White, D.A. 2015. The basics of least cost analysis for archaeological applications. Advances in Archaeological Practice 3(4): 407-414.

Whitley, T.G.; Hicks, L.M. 2003. A geographic information systems approach to understanding potential prehistoric and historic travel corridors. Southeastern Archaeology 22(1): 77-91.

Wiesemann, U. 1978. Os dialetos da língua Kaingáng e o Xokléng. Arquivos de Anatomia e Antropologia III: 199-217.

Yanchar, K.C. 2013. Degree and scale of interactions among chiefdoms during the pre-Hispanic late period in northern Highland Ecuador (AD 12501525). Dissertação de mestrado. Oregon State University, Eugene. 


\section{Apêndice}

Localização e datações dos sítios arqueológicos ativos entre 2000-500 anos cal AP no litoral sul de Santa Catarina (sítios ordenados de acordo com a sequência da Fig. 3)

\begin{tabular}{|c|c|c|c|c|c|c|}
\hline Sítio (Tipo) & UTM (22J) & Datas ${ }^{14} \mathrm{C}$ & $\begin{array}{c}\text { anos } \\
\text { cal AP }\end{array}$ & Material & Laboratório & Fonte \\
\hline $\begin{array}{l}\text { Cabeçuda I } \\
\text { (Sambaqui) }\end{array}$ & $712601 / 6852170$ & $\begin{array}{c}(4120 \pm 220) \\
4120 \pm 351\end{array}$ & $5579-3695$ & carvão & $\begin{array}{c}\text { Hannover } \\
167\end{array}$ & $\begin{array}{c}\text { Geyh \& } \\
\text { Schneekloth } \\
\text { (1964) }\end{array}$ \\
\hline Cabeçuda I & $712601 / 6852170$ & $4180 \pm 60$ & $4776-4405$ & concha & Beta 280006 & Saladino (2016) \\
\hline Cabeçuda I & $712601 / 6852170$ & $4180 \pm 60$ & $4776-4405$ & concha & Beta 280008 & Saladino (2016) \\
\hline Cabeçuda I & $712601 / 6852170$ & $4020 \pm 50$ & $4499-4175$ & concha & Beta 280007 & Saladino (2016) \\
\hline Cabeçuda I & $712601 / 6852170$ & $3870 \pm 40$ & $4351-4013$ & colágeno & Beta 280009 & Saladino (2016) \\
\hline Cabeçuda I & $712601 / 6852170$ & $3640 \pm 50$ & $3976-3662$ & concha & Beta 280005 & Saladino (2016) \\
\hline Cabeçuda I & $712601 / 6852170$ & $3030 \pm 30$ & $3210-3005$ & colágeno & Beta 383566 & $\begin{array}{c}\text { Farias \& } \\
\text { DeBlasis (2014) }\end{array}$ \\
\hline Cabeçuda I & $712601 / 6852170$ & $2920 \pm 30$ & $3060-2865$ & colágeno & Beta 383567 & $\begin{array}{c}\text { Farias \& } \\
\text { DeBlasis (2014) }\end{array}$ \\
\hline Cabeçuda I & $712601 / 6852170$ & $2290 \pm 30$ & $2318-2145$ & colágeno & Beta 297834 & Saladino (2016) \\
\hline Cabeçuda I & $712601 / 6852170$ & $2290 \pm 30$ & $2318-2145$ & colágeno & Beta 383565 & $\begin{array}{c}\text { Farias \& } \\
\text { DeBlasis (2014) }\end{array}$ \\
\hline Cabeçuda I & $712601 / 6852170$ & $2030 \pm 30$ & $1988-1830$ & colágeno & Beta 297831 & Saladino (2016) \\
\hline Cabeçuda I & $712601 / 6852170$ & $1990 \pm 30$ & 1930-1751 & colágeno & Beta 297832 & Saladino (2016) \\
\hline Cabeçuda I & $712601 / 6852170$ & $1800 \pm 40$ & $1721-1536$ & colágeno & Beta 297833 & Saladino (2016) \\
\hline $\begin{array}{l}\text { Encantada III } \\
\text { (Sambaqui) }\end{array}$ & $703806 / 6831498$ & $4420 \pm 50$ & $5028-4718$ & concha & Az 10638 & $\begin{array}{c}\text { DeBlasis } \\
\text { et al. (2007) }\end{array}$ \\
\hline Encantada III & $703806 / 6831498$ & $4320 \pm 40$ & $4971-4651$ & carvão & Beta 189713 & $\begin{array}{c}\text { DeBlasis } \\
\text { et al. (2007) }\end{array}$ \\
\hline Encantada III & $703806 / 6831498$ & $740 \pm 40$ & $721-560$ & carvão & Beta 189712 & $\begin{array}{l}\text { DeBlasis } \\
\text { et al. (2007) }\end{array}$ \\
\hline $\begin{array}{c}\text { Jabuticabeira I } \\
\text { (Sambaqui) }\end{array}$ & $697334 / 6837666$ & $4185 \pm 90$ & $4854-4433$ & carvão & Az 10639 & $\begin{array}{c}\text { DeBlasis } \\
\text { et al. (2007) }\end{array}$ \\
\hline Jabuticabeira I & $697334 / 6837666$ & $3995 \pm 85$ & $4802-4102$ & carvão & Az 10640 & $\begin{array}{c}\text { DeBlasis et al. } \\
(2007)\end{array}$ \\
\hline Jabuticabeira I & $697334 / 6837666$ & $2655 \pm 110$ & $2945-2363$ & carvão & Az 10641 & $\begin{array}{l}\text { DeBlasis } \\
\text { et al. (2007) }\end{array}$ \\
\hline Jabuticabeira I & $697334 / 6837666$ & $2430 \pm 125$ & $2749-2154$ & carvão & Az 10642 & $\begin{array}{c}\text { DeBlasis } \\
\text { et al. (2007) }\end{array}$ \\
\hline $\begin{array}{l}\text { Garopaba do Sul } \\
\text { (Sambaqui) }\end{array}$ & $706046 / 6831728$ & $4110 \pm 70$ & $4697-4240$ & concha & $\begin{array}{l}\text { CENA } \\
\text { LS-28 } \\
\end{array}$ & $\begin{array}{c}\text { DeBlasis } \\
\text { et al. (2007) }\end{array}$ \\
\hline Garopaba do Sul & $706046 / 6831728$ & $3450 \pm 180$ & $4217-3227$ & & & $\begin{array}{l}\text { DeBlasis } \\
\text { et al. (2007) }\end{array}$ \\
\hline Garopaba do Sul & $706046 / 6831728$ & $3960 \pm 50$ & $4518-4158$ & & Beta 253666 & $\begin{array}{l}\text { Kneip, Farias \& } \\
\text { DeBlasis (2018) }\end{array}$ \\
\hline
\end{tabular}


Análises de mobilidade no litoral sul de Santa Catarina entre 2000-500 anos cal AP

R. Museu Arq. Etn., 36: 59-94, 2021.

\begin{tabular}{|c|c|c|c|c|c|c|}
\hline Sítio (Tipo) & UTM (22J) & Datas ${ }^{14} \mathrm{C}$ & $\begin{array}{c}\text { anos } \\
\text { cal AP }\end{array}$ & Material & Laboratório & Fonte \\
\hline Garopaba do Sul & $706046 / 6831728$ & $3780 \pm 70$ & $4230-3815$ & concha & $\begin{array}{l}\text { CENA } \\
\text { LS-25 }\end{array}$ & $\begin{array}{c}\text { DeBlasis } \\
\text { et al. (2007) }\end{array}$ \\
\hline Garopaba do Sul & $706046 / 6831728$ & $3780 \pm 70$ & $4230-3815$ & concha & $\begin{array}{l}\text { CENA } \\
\text { LS-27 } \\
\end{array}$ & $\begin{array}{c}\text { DeBlasis } \\
\text { et al. }(2007)\end{array}$ \\
\hline Garopaba do Sul & $706046 / 6831728$ & $2705 \pm 240$ & $3380-2161$ & carvão & Az 10032 & $\begin{array}{c}\text { DeBlasis } \\
\text { et al. (2007) }\end{array}$ \\
\hline Garopaba do Sul & $706046 / 6831728$ & $2840 \pm 70$ & $3137-2757$ & carvão & $\mathrm{Az} 9888$ & $\begin{array}{l}\text { DeBlasis } \\
\text { et al. (2007) }\end{array}$ \\
\hline $\begin{array}{c}\text { Carniça I } \\
\text { (Sambaqui) }\end{array}$ & $714001 / 6840968$ & $\begin{array}{c}(3370 \pm 150) \\
3370 \pm 281 \\
\end{array}$ & $4400-2879$ & carvão & A 918 & Hurt (1974) \\
\hline Carniça I & $714001 / 6840968$ & $\begin{array}{c}(3370 \pm 110) \\
3370 \pm 241 \\
\end{array}$ & $4236-2961$ & carvão & A 919 & Hurt (1974) \\
\hline Carniça I & $714001 / 6840968$ & $\begin{array}{c}(3310 \pm 140) \\
3310 \pm 271\end{array}$ & $4125-2764$ & concha & A 912 & Hurt (1974) \\
\hline Carniça I & $714001 / 6840968$ & $\begin{array}{c}(3210 \pm 150) \\
3210 \pm 281 \\
\end{array}$ & $4074-2675$ & concha & A 917 & Hurt (1974) \\
\hline Carniça I & $714001 / 6840968$ & $\begin{array}{c}(3040 \pm 50) \\
3040 \pm 181 \\
\end{array}$ & $3543-2704$ & concha & A 883.2 & Hurt (1974) \\
\hline Carniça I & $714001 / 6840968$ & $\begin{array}{c}(2550 \pm 110) \\
2550 \pm 241\end{array}$ & $3100-1910$ & concha & A 914 & Hurt (1974) \\
\hline Carniça I & $714001 / 6840968$ & $\begin{array}{c}(2410 \pm 110) \\
2410 \pm 241 \\
\end{array}$ & 2991-1833 & carvão & A 884 & Hurt (1974) \\
\hline $\begin{array}{l}\text { Carniça I A } \\
\text { (sambaqui) }\end{array}$ & $714001 / 6840968$ & $\begin{array}{c}(3400 \pm 150) \\
3400 \pm 281 \\
\end{array}$ & $4290-2841$ & concha & $\begin{array}{c}\text { Lamont } \\
116449 \\
\end{array}$ & Hurt (1974) \\
\hline Carniça I A & $714001 / 6840968$ & $\begin{array}{c}(3275 \pm 125) \\
3275 \pm 256\end{array}$ & $4147-2805$ & carvão & A 950 & Hurt (1974) \\
\hline Carniça I A & $714001 / 6840968$ & $\begin{array}{c}(3300 \pm 150) \\
3300 \pm 281\end{array}$ & $4146-2741$ & concha & $\begin{array}{c}\text { Lamont } \\
1164 \mathrm{~B} \\
\end{array}$ & Hurt (1974) \\
\hline Carniça I A & $714001 / 6840968$ & $\begin{array}{c}(3280 \pm 120) \\
3280 \pm 251\end{array}$ & $4145-2850$ & carvão & A 956 & $\begin{array}{c}\text { Haynes, Grey \& } \\
\text { Long (1971) }\end{array}$ \\
\hline Carniça I A & $714001 / 6840968$ & $\begin{array}{c}(3350 \pm 110) \\
3350 \pm 241\end{array}$ & $4098-2858$ & concha & $\begin{array}{c}\text { Isotopes } \\
2620 \\
\end{array}$ & Hurt (1974) \\
\hline Carniça I A & $714001 / 6840968$ & $\begin{array}{c}(2460 \pm 100) \\
2460 \pm 231 \\
\end{array}$ & $2946-1826$ & concha & A 959 & Hurt (1974) \\
\hline $\begin{array}{c}\text { Caieira } \\
\text { (Sambaqui/ } \\
\text { Sambaqui tardio) }\end{array}$ & $717960 / 6848635$ & $\begin{array}{c}(2770 \pm 100) \\
2770 \pm 231\end{array}$ & $3352-2206$ & carvão & $\begin{array}{l}\text { Isotopes } \\
2628 \mathrm{C}\end{array}$ & Hurt (1974) \\
\hline Caieira & $717960 / 6848635$ & $\begin{array}{c}(3230 \pm 155) \\
3230 \pm 286\end{array}$ & $4155-2750$ & concha & $\begin{array}{c}\text { Isotopes } \\
2628 \mathrm{~S}\end{array}$ & Hurt (1974) \\
\hline Caieira & $717960 / 6848635$ & $\begin{array}{l}(710 \pm 95) \\
710 \pm 226 \\
\end{array}$ & $1074-152$ & carvão & $\begin{array}{c}\text { Isotopes } \\
2624 \\
\end{array}$ & Hurt (1974) \\
\hline $\begin{array}{l}\text { Morro do Peralta } \\
\text { (Sambaqui/ } \\
\text { Sambaqui tardio/ } \\
\text { Guarani) }\end{array}$ & $717035 / 6846624$ & $3550 \pm 50$ & $3921-3638$ & & Beta 262749 & $\begin{array}{l}\text { Kneip, Farias \& } \\
\text { DeBlasis (2018) }\end{array}$ \\
\hline
\end{tabular}




\begin{tabular}{|c|c|c|c|c|c|c|}
\hline Sítio (Tipo) & UTM (22J) & Datas ${ }^{14} \mathrm{C}$ & $\begin{array}{c}\text { anos } \\
\text { cal AP }\end{array}$ & Material & Laboratório & Fonte \\
\hline Morro do Peralta & $717035 / 6846624$ & $1490 \pm 40$ & $1411-1292$ & & Beta 262750 & $\begin{array}{l}\text { Kneip, Farias \& } \\
\text { DeBlasis (2018) }\end{array}$ \\
\hline $\begin{array}{c}\text { Jabuticabeira II } \\
\text { (Sambaqui/ } \\
\text { Sambaqui tardio) }\end{array}$ & $699489 / 6835694$ & $3200 \pm 50$ & $3547-3224$ & & Beta 253672 & $\begin{array}{l}\text { Kneip, Farias \& } \\
\text { DeBlasis (2018) }\end{array}$ \\
\hline Jabuticabeira II & $699489 / 6835694$ & $2880 \pm 75$ & $3165-2779$ & carvão & Az 9880 & $\begin{array}{c}\text { DeBlasis } \\
\text { et al. }(2007)\end{array}$ \\
\hline Jabuticabeira II & $699489 / 6835694$ & $2890 \pm 55$ & $3045-2749$ & concha & Az 10633 & $\begin{array}{c}\text { DeBlasis } \\
\text { et al. }(2007)\end{array}$ \\
\hline Jabuticabeira II & $699489 / 6835694$ & $2795 \pm 35$ & $2880-2710$ & concha & Az 10247 & $\begin{array}{c}\text { DeBlasis } \\
\text { et al. (2007) }\end{array}$ \\
\hline Jabuticabeira II & $699489 / 6835694$ & $2855 \pm 105$ & $3168-2653$ & concha & Az 10631 & $\begin{array}{c}\text { DeBlasis } \\
\text { et al. (2007) }\end{array}$ \\
\hline Jabuticabeira II & $699489 / 6835694$ & $2760 \pm 320$ & $3080-2440$ & $\begin{array}{c}\text { sedimento } \\
(\mathrm{LOE})\end{array}$ & UW 1412 & Assunção (2010) \\
\hline Jabuticabeira II & $699489 / 6835694$ & $2655 \pm 105$ & $2926-2363$ & carvão & Az 10636 & $\begin{array}{c}\text { DeBlasis } \\
\text { et al. }(2007)\end{array}$ \\
\hline Jabuticabeira II & $699489 / 6835694$ & $2470 \pm 55$ & $2709-2351$ & carvão & Az 9882 & $\begin{array}{c}\text { DeBlasis } \\
\text { et al. }(2007)\end{array}$ \\
\hline Jabuticabeira II & $699489 / 6835694$ & $2490 \pm 35$ & $2591-2306$ & concha & $\mathrm{Az} 10244$ & $\begin{array}{c}\text { DeBlasis } \\
\text { et al. (2007) }\end{array}$ \\
\hline Jabuticabeira II & $699489 / 6835694$ & $2530 \pm 300$ & $2830-2230$ & $\begin{array}{c}\text { sedimento } \\
(\mathrm{LOE})\end{array}$ & UW 1410 & Assunção (2010) \\
\hline Jabuticabeira II & $699489 / 6835694$ & $2500 \pm 155$ & $2871-2149$ & carvão & Az 9894 & $\begin{array}{c}\text { DeBlasis } \\
\text { et al. }(2007)\end{array}$ \\
\hline Jabuticabeira II & $699489 / 6835694$ & $2285 \pm 45$ & $2346-2145$ & carvão & Az 9890 & $\begin{array}{c}\text { DeBlasis } \\
\text { et al. (2007) }\end{array}$ \\
\hline Jabuticabeira II & $699489 / 6835694$ & $2370 \pm 35$ & $2349-2140$ & concha & Az 10245 & $\begin{array}{l}\text { DeBlasis } \\
\text { et al. (2007) }\end{array}$ \\
\hline Jabuticabeira II & $699489 / 6835694$ & $2340 \pm 50$ & $2362-2123$ & colágeno & Beta 188381 & $\begin{array}{c}\text { DeBlasis } \\
\text { et al. }(2007)\end{array}$ \\
\hline Jabuticabeira II & $699489 / 6835694$ & $2320 \pm 50$ & $2350-2122$ & colágeno & Beta 188382 & $\begin{array}{c}\text { DeBlasis } \\
\text { et al. (2007) }\end{array}$ \\
\hline Jabuticabeira II & $699489 / 6835694$ & $2335 \pm 35$ & $2324-2119$ & concha & Az 10246 & $\begin{array}{c}\text { DeBlasis } \\
\text { et al. (2007) }\end{array}$ \\
\hline Jabuticabeira II & $699489 / 6835694$ & $2365 \pm 45$ & $2365-2115$ & concha & Az 10243 & $\begin{array}{c}\text { DeBlasis } \\
\text { et al. (2007) }\end{array}$ \\
\hline Jabuticabeira II & $699489 / 6835694$ & $2345 \pm 105$ & $2711-2085$ & carvão & Az 9889 & $\begin{array}{c}\text { DeBlasis } \\
\text { et al. }(2007)\end{array}$ \\
\hline Jabuticabeira II & $699489 / 6835694$ & $2310 \pm 70$ & $2485-2085$ & carvão & Az 10632 & $\begin{array}{c}\text { DeBlasis } \\
\text { et al. (2007) }\end{array}$ \\
\hline Jabuticabeira II & $699489 / 6835694$ & $2210 \pm 60$ & $2326-2016$ & carvão & Az 9893 & $\begin{array}{c}\text { DeBlasis } \\
\text { et al. (2007) }\end{array}$ \\
\hline
\end{tabular}


Análises de mobilidade no litoral sul de Santa Catarina entre 2000-500 anos cal AP

R. Museu Arq. Etn., 36: 59-94, 2021.

\begin{tabular}{|c|c|c|c|c|c|c|}
\hline Sítio (Tipo) & UTM (22J) & Datas ${ }^{14} \mathrm{C}$ & $\begin{array}{c}\text { anos } \\
\text { cal AP }\end{array}$ & Material & Laboratório & Fonte \\
\hline Jabuticabeira II & $699489 / 6835694$ & $2270 \pm 75$ & $2359-2015$ & carvão & Az 9898 & $\begin{array}{c}\text { DeBlasis } \\
\text { et al. }(2007)\end{array}$ \\
\hline Jabuticabeira II & $699489 / 6835694$ & $2280 \pm 80$ & $2430-2013$ & carvão & Az 10634 & $\begin{array}{c}\text { DeBlasis } \\
\text { et al. (2007) }\end{array}$ \\
\hline Jabuticabeira II & $699489 / 6835694$ & $2295 \pm 90$ & $2677-2010$ & carvão & Az 9891 & $\begin{array}{c}\text { DeBlasis } \\
\text { et al. (2007) }\end{array}$ \\
\hline Jabuticabeira II & $699489 / 6835694$ & $2170 \pm 45$ & $2305-2005$ & carvão & Az 9896 & $\begin{array}{c}\text { DeBlasis } \\
\text { et al. (2007) }\end{array}$ \\
\hline Jabuticabeira II & $699489 / 6835694$ & $2165 \pm 75$ & $2320-1930$ & carvão & Az 10637 & $\begin{array}{c}\text { DeBlasis } \\
\text { et al. }(2007)\end{array}$ \\
\hline Jabuticabeira II & $699489 / 6835694$ & $2120 \pm 200$ & $2320-1920$ & $\begin{array}{c}\text { sedimento } \\
(\mathrm{LOE})\end{array}$ & UW 1413 & Assunção (2010) \\
\hline Jabuticabeira II & $699489 / 6835694$ & $2170 \pm 95$ & $2341-1916$ & carvão & Az 9895 & $\begin{array}{c}\text { DeBlasis } \\
\text { et al. }(2007)\end{array}$ \\
\hline Jabuticabeira II & $699489 / 6835694$ & $2180 \pm 105$ & $2350-1890$ & carvão & Az 10635 & $\begin{array}{c}\text { DeBlasis } \\
\text { et al. (2007) }\end{array}$ \\
\hline Jabuticabeira II & $699489 / 6835694$ & $2115 \pm 65$ & $2304-1888$ & carvão & Az 9899 & $\begin{array}{c}\text { DeBlasis } \\
\text { et al. }(2007)\end{array}$ \\
\hline Jabuticabeira II & $699489 / 6835694$ & $2020 \pm 40$ & $2010-1835$ & carvão & Beta 195240 & $\begin{array}{c}\text { DeBlasis } \\
\text { et al. }(2007)\end{array}$ \\
\hline Jabuticabeira II & $699489 / 6835694$ & $2240 \pm 170$ & $2710-1835$ & carvão & Az 9883 & $\begin{array}{c}\text { DeBlasis } \\
\text { et al. (2007) }\end{array}$ \\
\hline Jabuticabeira II & $699489 / 6835694$ & $2075 \pm 65$ & $2291-1834$ & carvão & Az 9881 & $\begin{array}{c}\text { DeBlasis } \\
\text { et al. (2007) }\end{array}$ \\
\hline Jabuticabeira II & $699489 / 6835694$ & $2028 \pm 44$ & $2044-1832$ & & Az AA77106 & $\begin{array}{l}\text { Kneip, Farias \& } \\
\text { DeBlasis (2018) }\end{array}$ \\
\hline Jabuticabeira II & $699489 / 6835694$ & $2004 \pm 44$ & $2011-1823$ & & Az AA77105 & $\begin{array}{l}\text { Kneip, Farias \& } \\
\text { DeBlasis }(2018)\end{array}$ \\
\hline Jabuticabeira II & $699489 / 6835694$ & $1990 \pm 190$ & $2180-1800$ & $\begin{array}{l}\text { sedimento } \\
\text { (LOE) }\end{array}$ & UW 1411 & Assunção (2010) \\
\hline Jabuticabeira II & $699489 / 6835694$ & $1970 \pm 40$ & $1998-1748$ & carvão & Beta 195249 & $\begin{array}{c}\text { DeBlasis } \\
\text { et al. (2007) }\end{array}$ \\
\hline Jabuticabeira II & $699489 / 6835694$ & $2060 \pm 85$ & $2301-1747$ & carvão & Az 9897 & $\begin{array}{c}\text { DeBlasis } \\
\text { et al. }(2007)\end{array}$ \\
\hline Jabuticabeira II & $699489 / 6835694$ & $2070 \pm 60$ & $2073-1735$ & concha & Beta 195239 & $\begin{array}{c}\text { DeBlasis } \\
\text { et al. (2007) }\end{array}$ \\
\hline Jabuticabeira II & $699489 / 6835694$ & $1950 \pm 70$ & $2013-1635$ & carvão & Beta 195250 & $\begin{array}{c}\text { DeBlasis } \\
\text { et al. }(2007)\end{array}$ \\
\hline Jabuticabeira II & $699489 / 6835694$ & $1910 \pm 60$ & $1992-1617$ & carvão & Beta 228507 & Nishida (2007), \\
\hline Jabuticabeira II & $699489 / 6835694$ & $1975 \pm 95$ & $2147-1614$ & carvão & $\mathrm{Az} 9900$ & $\begin{array}{c}\text { DeBlasis } \\
\text { et al. }(2007)\end{array}$ \\
\hline Jabuticabeira II & $699489 / 6835694$ & $1850 \pm 40$ & $1834-1611$ & carvão & $\mathrm{Az}$ 9885a & $\begin{array}{c}\text { DeBlasis } \\
\text { et al. (2007) }\end{array}$ \\
\hline
\end{tabular}




\begin{tabular}{|c|c|c|c|c|c|c|}
\hline Sítio (Tipo) & UTM (22J) & Datas ${ }^{14} \mathrm{C}$ & $\begin{array}{c}\text { anos } \\
\text { cal AP }\end{array}$ & Material & Laboratório & Fonte \\
\hline Jabuticabeira II & $699489 / 6835694$ & $1805 \pm 65$ & $1833-1536$ & carvão & Az 9884 & $\begin{array}{c}\text { DeBlasis } \\
\text { et al. (2007) }\end{array}$ \\
\hline Jabuticabeira II & $699489 / 6835694$ & $1895 \pm 185$ & $2303-1376$ & carvão & Az 9892 & $\begin{array}{c}\text { DeBlasis } \\
\text { et al. (2007) }\end{array}$ \\
\hline Jabuticabeira II & $699489 / 6835694$ & $1540 \pm 50$ & $1515-1310$ & carvão & Beta 228506 & Nishida (2007) \\
\hline Jabuticabeira II & $699489 / 6835694$ & $1400 \pm 40$ & $1304-1124$ & colágeno & Beta 234201 & $\begin{array}{l}\text { Kneip, Farias \& } \\
\text { DeBlasis (2018) }\end{array}$ \\
\hline $\begin{array}{l}\text { Mato Alto I (Sam- } \\
\text { baqui) }\end{array}$ & $698773 / 6842162$ & $2245 \pm 60$ & $2345-2060$ & carvão & Az 10643 & $\begin{array}{c}\text { DeBlasis } \\
\text { et al. (2007) }\end{array}$ \\
\hline $\begin{array}{c}\text { Ribeirão Pequeno } \\
\text { (Sambaqui) }\end{array}$ & $706331 / 6842857$ & $2390 \pm 70$ & $2507-2087$ & concha & Beta 209704 & $\begin{array}{c}\text { DeBlasis } \\
\text { et al. (2007) }\end{array}$ \\
\hline $\begin{array}{c}\text { Encruzo } \\
\text { (Sambaqui } \\
\text { tardio/Guarani) }\end{array}$ & $691910 / 6835037$ & $2410 \pm 50$ & $2467-2148$ & concha & Beta 270327 & Milheira (2010) \\
\hline Encruzo & $691910 / 6835037$ & $1970 \pm 25$ & $1987-1823$ & carvão & $\begin{array}{c}\text { UGAMS } \\
32417\end{array}$ & $\begin{array}{l}\text { DeBlasis et al. } \\
\text { (2018) inédita }\end{array}$ \\
\hline $\begin{array}{c}\text { Morrote } \\
\text { (Sambaqui/ } \\
\text { Sambaqui tardio) }\end{array}$ & $699360 / 6840440$ & $2075 \pm 110$ & $2309-1746$ & carvão & $\mathrm{Az} 9886$ & $\begin{array}{c}\text { DeBlasis } \\
\text { et al. (2007) }\end{array}$ \\
\hline Morrote & $699360 / 6840440$ & $1975 \pm 115$ & $2290-1589$ & carvão & Az 9887 & $\begin{array}{c}\text { DeBlasis } \\
\text { et al. (2007) }\end{array}$ \\
\hline $\begin{array}{l}\text { Congonhas III } \\
\text { (Sambaqui) }\end{array}$ & $694320 / 6838450$ & $2115 \pm 50$ & $2299-1915$ & carvão & Az 10646 & $\begin{array}{c}\text { DeBlasis } \\
\text { et al. (2007) }\end{array}$ \\
\hline $\begin{array}{c}\text { Santa Marta V } \\
\text { (Sambaqui) }\end{array}$ & $711521 / 6835084$ & $2090 \pm 50$ & $2151-1894$ & & Beta 234196 & $\begin{array}{l}\text { Kneip, Farias \& } \\
\text { DeBlasis (2018) }\end{array}$ \\
\hline Santa Marta V & $711521 / 6835084$ & $1990 \pm 40$ & $2004-1756$ & & Beta 234197 & $\begin{array}{l}\text { Kneip, Farias \& } \\
\text { DeBlasis (2018) }\end{array}$ \\
\hline $\begin{array}{l}\text { Lagoa do Bixos IV } \\
\text { (Sambaqui tardio) }\end{array}$ & $716393 / 6840284$ & $4070 \pm 50$ & $4560-4240$ & concha & Beta 234204 & $\begin{array}{l}\text { Kneip, Farias \& } \\
\text { DeBlasis (2018) }\end{array}$ \\
\hline $\begin{array}{c}\text { Ponta das Laran- } \\
\text { jeiras II (Samba- } \\
\text { qui tardio) }\end{array}$ & $711893 / 6854240$ & $2010 \pm 50$ & $2045-1752$ & & Beta 270328 & $\begin{array}{l}\text { Kneip, Farias \& } \\
\text { DeBlasis (2018) }\end{array}$ \\
\hline $\begin{array}{c}\text { Pedra Chata } \\
\text { (Sambaqui tardio) }\end{array}$ & $711044 / 6852155$ & $2040 \pm 30$ & $1975-1765$ & concha & Beta 383570 & $\begin{array}{c}\text { Farias \& } \\
\text { DeBlasis (2014) }\end{array}$ \\
\hline $\begin{array}{c}\text { Morro Grande II } \\
\text { (Sambaqui tardio) }\end{array}$ & $687156 / 6823584$ & $1890 \pm 25$ & $1864-1715$ & carvão & $\begin{array}{c}\text { UGAMS } \\
32429 \\
\end{array}$ & $\begin{array}{l}\text { DeBlasis et al. } \\
\text { (2018) inédita }\end{array}$ \\
\hline Morro Grande II & $687156 / 6823584$ & $1840 \pm 30$ & $1825-1612$ & semente & Beta 553739 & inédita \\
\hline Morro Grande II & $687156 / 6823584$ & $1800 \pm 30$ & $1741-1586$ & semente & Beta 553740 & inédita \\
\hline $\begin{array}{c}\text { Santa Marta } \\
\text { VIII (Sambaqui } \\
\text { tardio/Guarani) }\end{array}$ & $711519 / 6835139$ & $1710 \pm 40$ & $1619-1405$ & colágeno & Beta 253668 & Villagran (2012) \\
\hline $\begin{array}{c}\text { Içara } 01 \\
\text { (Sambaqui tardio) }\end{array}$ & $665807 / 6804475$ & $1580 \pm 50$ & $1533-1320$ & carvão & Beta 72196 & $\begin{array}{c}\text { Schmitz et al. } \\
\text { (1999) }\end{array}$ \\
\hline
\end{tabular}


Análises de mobilidade no litoral sul de Santa Catarina entre 2000-500 anos cal AP

R. Museu Arq. Etn., 36: 59-94, 2021.

\begin{tabular}{|c|c|c|c|c|c|c|}
\hline Sítio (Tipo) & UTM (22J) & Datas ${ }^{14} \mathrm{C}$ & $\begin{array}{c}\text { anos } \\
\text { cal AP }\end{array}$ & Material & Laboratório & Fonte \\
\hline Içara 01 & $665807 / 6804475$ & $1450 \pm 60$ & $1416-1185$ & carvão & Beta 72197 & $\begin{array}{c}\text { Schmitz et al. } \\
\text { (1999) }\end{array}$ \\
\hline $\begin{array}{l}\text { Lagoa dos Freitas } \\
\text { (Sambaqui } \\
\text { tardio/Guarani) }\end{array}$ & $673708 / 6812150$ & $1460 \pm 30$ & $1364-1280$ & carvão & Beta 403222 & $\begin{array}{l}\text { Santos, Pavei \& } \\
\text { Campos (2018) }\end{array}$ \\
\hline Lagoa dos Freitas & $673708 / 6812150$ & $1430 \pm 30$ & $1353-1270$ & carvão & Beta 426824 & $\begin{array}{l}\text { Santos, Pavei \& } \\
\text { Campos (2018) } \\
\end{array}$ \\
\hline Lagoa dos Freitas & $673708 / 6812150$ & $390 \pm 30$ & $492-323$ & carvão & Beta 403220 & $\begin{array}{l}\text { Santos, Pavei \& } \\
\text { Campos (2018) }\end{array}$ \\
\hline Lagoa dos Freitas & $673708 / 6812150$ & $360 \pm 30$ & $309-168$ & carvão & Beta 403221 & $\begin{array}{l}\text { Santos, Pavei \& } \\
\text { Campos (2018) }\end{array}$ \\
\hline Lagoa dos Freitas & $673708 / 6812150$ & $90 \pm 30$ & $240-20$ & carvão & Beta 426825 & $\begin{array}{l}\text { Santos, Pavei \& } \\
\text { Campos (2018) } \\
\end{array}$ \\
\hline $\begin{array}{c}\text { Figueirinha V } \\
\text { (Sambaqui tardio) }\end{array}$ & $696603 / 6827628$ & $1470 \pm 25$ & $1307-1173$ & concha & $\begin{array}{c}\text { UGAMS } \\
18550 \\
\end{array}$ & Attorre (2015) \\
\hline $\begin{array}{c}\text { Galheta IV } \\
\text { (Monticular } \\
\text { Itararé-Taquara) }\end{array}$ & $716263 / 6838043$ & $1360 \pm 40$ & $1276-1088$ & colágeno & Beta 280010 & $\begin{array}{c}\text { DeBlasis, } \\
\text { Farias \& } \\
\text { Kneip (2014) }\end{array}$ \\
\hline Galheta IV & $716263 / 6838043$ & $1070 \pm 40$ & $925-726$ & $\begin{array}{l}\text { lobo } \\
\text { marinho }\end{array}$ & Beta 280011 & $\begin{array}{c}\text { DeBlasis, } \\
\text { Farias \& } \\
\text { Kneip (2014) }\end{array}$ \\
\hline Galheta IV & $716263 / 6838043$ & $990 \pm 44$ & $913-723$ & colágeno & $\begin{array}{l}\text { UGAMS } \\
30090\end{array}$ & $\begin{array}{c}\text { DeBlasis } \\
\text { et al. }(2018), \\
\text { Cardoso (2019) }\end{array}$ \\
\hline Galheta IV & $716263 / 6838043$ & $980 \pm 40$ & $908-717$ & colágeno & Beta 211734 & $\begin{array}{c}\text { DeBlasis, } \\
\text { Farias \& Kneip } \\
(2014)\end{array}$ \\
\hline Galheta IV & $716263 / 6838043$ & $950 \pm 40$ & $890-679$ & colágeno & Beta 280012 & $\begin{array}{c}\text { DeBlasis, } \\
\text { Farias \& Kneip } \\
(2014) \\
\end{array}$ \\
\hline Galheta IV & $716263 / 6838043$ & $830 \pm 43$ & $739-565$ & colágeno & $\begin{array}{l}\text { UGAMS } \\
30089\end{array}$ & $\begin{array}{c}\text { DeBlasis } \\
\text { et al. (2018), } \\
\text { Cardoso (2019) }\end{array}$ \\
\hline $\begin{array}{c}\text { Morro Grande I } \\
\text { (Sambaqui tardio) }\end{array}$ & $687098 / 6824050$ & $1310 \pm 25$ & $1274-1093$ & carvão & $\begin{array}{c}\text { UGAMS } \\
32428\end{array}$ & $\begin{array}{l}\text { DeBlasis et al. } \\
\text { (2018) inédita }\end{array}$ \\
\hline Morro Grande I & $687098 / 6824050$ & $1220 \pm 25$ & $1179-985$ & carvão & $\begin{array}{c}\text { UGAMS } \\
32427 \\
\end{array}$ & $\begin{array}{l}\text { DeBlasis et al. } \\
\text { (2018) inédita }\end{array}$ \\
\hline Morro Grande I & $687098 / 6824050$ & $1210 \pm 30$ & $1178-978$ & semente & Beta 553738 & $\begin{array}{l}\text { esta pesquisa } \\
\text { (inédita) }\end{array}$ \\
\hline $\begin{array}{l}\text { Aldeia ZPE } \\
\text { (Guarani) }\end{array}$ & $727864 / 6876354$ & $1050 \pm 150$ & $1301-701$ & $\begin{array}{l}\text { sedimento } \\
\text { (TL) }\end{array}$ & & $\begin{array}{c}\text { Santos, } \\
\text { Milheira \& } \\
\text { Campos (2017) }\end{array}$ \\
\hline Aldeia ZPE & $727864 / 6876354$ & $1040 \pm 110$ & $1211-771$ & $\begin{array}{l}\text { cerâmica } \\
\text { (TL) }\end{array}$ & & $\begin{array}{c}\text { Santos, } \\
\text { Milheira \& } \\
\text { Campos (2017) } \\
\end{array}$ \\
\hline
\end{tabular}




\begin{tabular}{|c|c|c|c|c|c|c|}
\hline Sítio (Tipo) & UTM (22J) & Datas ${ }^{14} \mathrm{C}$ & $\begin{array}{c}\text { anos } \\
\text { cal AP }\end{array}$ & Material & Laboratório & Fonte \\
\hline Aldeia ZPE & $727864 / 6876354$ & $1000 \pm 110$ & $1171-731$ & $\begin{array}{l}\text { cerâmica } \\
\text { (TL) }\end{array}$ & & $\begin{array}{c}\text { Santos, } \\
\text { Milheira \& } \\
\text { Campos }(2017)\end{array}$ \\
\hline Aldeia ZPE & $727864 / 6876354$ & $810 \pm 85$ & $931-541$ & $\begin{array}{l}\text { sedimento } \\
\text { (TL) }\end{array}$ & & $\begin{array}{c}\text { Santos, } \\
\text { Milheira \& } \\
\text { Campos (2017) }\end{array}$ \\
\hline Aldeia ZPE & $727864 / 6876354$ & $715 \pm 75$ & $816-516$ & $\begin{array}{l}\text { sedimento } \\
\text { (TL) }\end{array}$ & & $\begin{array}{c}\text { Santos, } \\
\text { Milheira \& } \\
\text { Campos (2017) }\end{array}$ \\
\hline $\begin{array}{l}\text { Campo Bom I } \\
\text { (Conchífero } \\
\text { Itararé-Taquara) }\end{array}$ & $687316 / 6820079$ & $1160 \pm 40$ & $1041-811$ & concha & Beta 211732 & $\begin{array}{l}\text { DeBlasis et al. } \\
\qquad(2007)\end{array}$ \\
\hline Campo Bom I & $687316 / 6820079$ & $1080 \pm 60$ & $965-699$ & concha & Beta 209703 & $\begin{array}{c}\text { DeBlasis } \\
\text { et al. (2007), } \\
\text { Farias et al. (2018) }\end{array}$ \\
\hline Campo Bom I & $687316 / 6820079$ & $650 \pm 25$ & $649-548$ & carvão & $\begin{array}{l}\text { UGAMS } \\
32416\end{array}$ & $\begin{array}{c}\text { DeBlasis } \\
\text { et al. (2018), } \\
\text { Farias et al. } \\
\text { (2018), inédita }\end{array}$ \\
\hline Campo Bom I & $687316 / 6820079$ & $620 \pm 25$ & $635-532$ & carvão & $\begin{array}{l}\text { UGAMS } \\
32414\end{array}$ & $\begin{array}{c}\text { DeBlasis } \\
\text { et al. (2018), } \\
\text { Farias et al. } \\
\text { (2018), inédita }\end{array}$ \\
\hline Campo Bom I & $687316 / 6820079$ & $580 \pm 25$ & $624-512$ & carvão & $\begin{array}{l}\text { UGAMS } \\
32415\end{array}$ & $\begin{array}{c}\text { DeBlasis } \\
\text { et al. (2018), } \\
\text { Farias et al. } \\
\text { (2018), inédita }\end{array}$ \\
\hline $\begin{array}{c}\text { Costão do Ilhote } \\
\text { de Santa Marta } \\
\text { (Monticular } \\
\text { Itararé-Taquara) } \\
\end{array}$ & $711421 / 6833152$ & $980 \pm 40$ & $928-764$ & carvão & Beta 211733 & $\begin{array}{l}\text { DeBlasis et al. } \\
\qquad(2007)\end{array}$ \\
\hline $\begin{array}{l}\text { Campo Bom } \\
\text { II (Conchífero } \\
\text { Itararé-Taquara) }\end{array}$ & $687570 / 6820279$ & $930 \pm 25$ & $905-731$ & carvão & $\begin{array}{l}\text { UGAMS } \\
32412\end{array}$ & $\begin{array}{l}\text { DeBlasis } \\
\text { et al. (2018), } \\
\text { Farias et al. } \\
\text { (2018), inédita }\end{array}$ \\
\hline Campo Bom II & $687570 / 6820279$ & $770 \pm 25$ & $723-575$ & carvão & $\begin{array}{l}\text { UGAMS } \\
32413\end{array}$ & $\begin{array}{c}\text { DeBlasis } \\
\text { et al. (2018), } \\
\text { Farias et al. } \\
\text { (2018), inédita }\end{array}$ \\
\hline $\begin{array}{c}\text { Baixo Rio D’Una } \\
\text { I (Guarani) }\end{array}$ & $725013 / 6879716$ & $910 \pm 30$ & $903-689$ & carvão & Beta 396226 & $\begin{array}{l}\text { Schwengber } \\
\text { (2015) }\end{array}$ \\
\hline $\begin{array}{l}\text { SC-ARA-021 } \\
\text { (Guarani) }\end{array}$ & $665644 / 6807591$ & $610 \pm 60$ & $681-441$ & $\begin{array}{l}\text { cerâmica } \\
\text { (TL) }\end{array}$ & & $\begin{array}{c}\text { Santos, } \\
\text { Milheira \& } \\
\text { Campos }(2017)\end{array}$ \\
\hline
\end{tabular}


Análises de mobilidade no litoral sul de Santa Catarina entre 2000-500 anos cal AP

R. Museu Arq. Etn., 36: 59-94, 2021.

\begin{tabular}{|c|c|c|c|c|c|c|}
\hline Sítio (Tipo) & UTM (22J) & Datas ${ }^{14} \mathrm{C}$ & $\begin{array}{c}\text { anos } \\
\text { cal AP }\end{array}$ & Material & Laboratório & Fonte \\
\hline $\begin{array}{l}\text { Campo Bom III } \\
\text { (Conchífero } \\
\text { Itararé-Taquara) }\end{array}$ & $687680 / 6820337$ & $830 \pm 25$ & $738-671$ & carvão & $\begin{array}{l}\text { UGAMS } \\
32410\end{array}$ & $\begin{array}{c}\text { DeBlasis } \\
\text { et al. (2018), } \\
\text { Farias et al. } \\
\text { (2018), inédita }\end{array}$ \\
\hline Campo Bom III & $687680 / 6820337$ & $870 \pm 25$ & $787-680$ & carvão & $\begin{array}{l}\text { UGAMS } \\
32411\end{array}$ & $\begin{array}{c}\text { DeBlasis } \\
\text { et al. (2018), } \\
\text { Farias et al. } \\
\text { (2018), inédita }\end{array}$ \\
\hline $\begin{array}{l}\text { SC-ARA-004 } \\
\text { (Guarani) }\end{array}$ & $663557 / 6805711$ & $720 \pm 70$ & $811-531$ & $\begin{array}{l}\text { cerâmica } \\
\text { (TL) }\end{array}$ & & $\begin{array}{c}\text { Santos, } \\
\text { Milheira \& } \\
\text { Campos (2017) }\end{array}$ \\
\hline Awyra (Guarani) & $726874 / 6880844$ & $\begin{array}{c}650-530 \\
\text { anos cal AP }\end{array}$ & & & & $\begin{array}{c}\text { Farias \& } \\
\text { Kneip (2010) }\end{array}$ \\
\hline Awyra & $726874 / 6880844$ & $\begin{array}{c}650-530 \\
\text { anos cal AP }\end{array}$ & & & & $\begin{array}{c}\text { Farias \& } \\
\text { Kneip (2010) }\end{array}$ \\
\hline $\begin{array}{l}\text { Arroio da Cruz } \\
\text { I (Conchífero } \\
\text { Itararé-Taquara) }\end{array}$ & $683548 / 6817524$ & $660 \pm 25$ & $651-552$ & carvão & $\begin{array}{l}\text { UGAMS } \\
32421\end{array}$ & $\begin{array}{c}\text { DeBlasis } \\
\text { et al. (2018), } \\
\text { Farias et al. } \\
\text { (2018), inédita }\end{array}$ \\
\hline Arroio da Cruz I & $683548 / 6817524$ & $610 \pm 25$ & $632-530$ & carvão & $\begin{array}{l}\text { UGAMS } \\
32420\end{array}$ & $\begin{array}{c}\text { DeBlasis } \\
\text { et al. (2018), } \\
\text { Farias et al. } \\
\text { (2018), inédita }\end{array}$ \\
\hline Silbeco (Guarani) & $701597 / 6832366$ & $550 \pm 60$ & $646-459$ & & Beta 262752 & Milheira (2010) \\
\hline $\begin{array}{c}\text { Cabeçuda II } \\
\text { (Guarani) }\end{array}$ & $714595 / 6850945$ & $\begin{array}{c}630-500 \\
\text { anos cal AP }\end{array}$ & & & & Assunção (2010) \\
\hline $\begin{array}{c}\text { Olho d'Água I } \\
\text { (Guarani) }\end{array}$ & $675956 / 6813757$ & $570 \pm 40$ & $630-500$ & carvão & Beta 280652 & Milheira (2010) \\
\hline $\begin{array}{c}\text { Morro Bonito I } \\
\text { (Guarani) }\end{array}$ & $699077 / 6833937$ & $520 \pm 50$ & $625-342$ & carvão & Beta 262753 & Milheira (2010) \\
\hline $\begin{array}{c}\text { Morro Bonito III } \\
\text { (Guarani) }\end{array}$ & $696340 / 6833244$ & $510 \pm 40$ & $552-469$ & carvão & Beta 262755 & Milheira (2010) \\
\hline $\begin{array}{c}\text { Arroio Corrente } \\
\text { V (Guarani) }\end{array}$ & $691901 / 6825308$ & $470 \pm 40$ & $541-330$ & carvão & Beta 280654 & Milheira (2010) \\
\hline $\begin{array}{c}\text { Cerâmico Laranjal } \\
1 \text { (Guarani) }\end{array}$ & $701597 / 6832366$ & $440 \pm 40$ & $519-325$ & carvão & Beta 262751 & Milheira (2010) \\
\hline $\begin{array}{c}\text { Morro Bonito II } \\
\text { (Guarani) }\end{array}$ & $697129 / 6833686$ & $430 \pm 40$ & $511-325$ & carvão & Beta 262754 & Milheira (2010) \\
\hline
\end{tabular}

